\title{
Bipolar disorder and neurophysiologic mechanisms
}

\author{
Simon M McCrea \\ Departments of Neurology \\ and Neuroophthalmology, University \\ of British Columbia, 2550 Willow \\ Street, Vancouver, British Columbia, \\ Canada V5Z 3N9
}

\begin{abstract}
Recent studies have suggested that some variants of bipolar disorder (BD) may be due to hyperconnectivity between orbitofrontal (OFC) and temporal pole (TP) structures in the dominant hemisphere. Some initial MRI studies noticed that there were corpus callosum abnormalities within specific regional areas and it was hypothesized that developmentally this could result in functional or effective connectivity changes within the orbitofrontal-basal ganglia-thalamocortical circuits. Recent diffusion tensor imaging (DTI) white matter fiber tractography studies may well be superior to region of interest (ROI) DTI in understanding BD. A "ventral semantic stream" has been discovered connecting the TP and OFC through the uncinate and inferior longitudinal fasciculi and the elusive TP is known to be involved in theory of mind and complex narrative understanding tasks. The OFC is involved in abstract valuation in goal and sub-goal structures and the TP may be critical in binding semantic memory with person-emotion linkages associated with narrative. BD patients have relative attenuation of performance on visuoconstructional praxis consistent with an atypical localization of cognitive functions. Multiple lines of evidence suggest that some BD alleles are being selected for which could explain the enhanced creativity in higher-ability probands. Associations between ROI's that are not normally connected could explain the higher incidence of artistic aptitude, writing ability, and scientific achievements among some mood disorder subjects.

Keywords: bipolar disorder, diffusion tensor imaging, white matter tractography, inferior longitudinal fasciculus, inferior fronto-occipital fasciculus, uncinate fasciculus, mood dysphoria, creativity, ventral semantic stream, writing ability, artistic aptitude
\end{abstract}

\section{Introduction}

There are reliable differences in regional callosal area across subjects with specific relationships to the organization of linguistic processes. Normal limit differences in width or regional fiber composition of the corpus callosum do have predictable effects on the patterns of inter- and intra-hemispheric of communication and hence in the transfer of information throughout the cerebral cortex (Clarke and Zaidel 1994). Developmentally speaking, thickness or thinning of specific regions of the callosum could accentuate the canalization of specific white matter pathways both interhemispherically and intrahemispherically. Between subject differences in the variance of regional fiber composition could even result in unique co-configurations of white matter tracts in men and women. Bipolar disorder has long been known to be concordant with either regionally reduced white matter density or more recently hyperconnectivity between specific regions of the human brain. However only recently has the disorder been reconceptualized theoretically as a complex disorder of connectivity.

In the cognitive neuropsychiatry and cognitive neuropsychology literature it has been shown that electrophysiological synchronous patterns of activation can coordinate up to four sensory regional modules in a single cyclic 100 millisecond reverbatory whole-brain circuit linking frontal and posterior cortical networks (Singer 2004). In normal individuals, language and praxis are co-localized to the left hemisphere with the left and right hemispheres sensitive to abstract and concrete concepts, respectively. 
In contrast in atypical language localized subjects language and praxis may be localized to the right and left hemispheres, respectively (Knecht et al 2003). In some of these individuals, abstract concepts may show a preponderance of association with the right hemisphere and concomitantly, concrete concepts will be largely processed with left hemisphere networks (Binder et al 2005).

In certain variants of bipolar disorder in susceptible individuals, the atypical co-localization of praxis and concrete concepts could function as a highly sensitive mapping mechanism in concert with the right hemisphere's abstract linguistic mapping function. However, this is only one of many possible subtypes. For our current purposes, we will focus on recent neuroanatomical studies that have clear theoretical implications for explaining the disorder with a particular emphasis on the "ventral semantic stream". Convergent findings across disciplines implicate this recently articulated white matter pathway in the etiology of bipolar disorder.

However not all bipolar disorder subjects show atypical patterns of cortical localization. Bipolar disorder is reliably associated with higher-order impairments fundamentally presenting as dysregulated mood homeostatic mechanisms. These dysregulated homeostatic mood mechanisms originate in the prefrontal to the limbic to the reticular formation top-down afferents. As a result, white or gray matter deficiencies anywhere in the distributed prefrontal neural networks will result in impairments in functional or effective connectivity such that the disorder can be conceived of as the end result of any combination of structural brain abnormalities. Such sophisticated system views of top-down prefrontal mediated networks could well benefit from some of the third generation computational modeling techniques that use both diffusion tensor imaging fiber tracking (eg, tractography) and vector autoregressive modeling techniques (Goebel et al 2004).

Indeed, recently just such approaches have left the theoretical cognitive neuroscience laboratory and entered neuropsychiatric research and practice. That bipolar disorder etiology is extremely heterogeneous yet convergent in resultant symptomologic profile suggests dysfunction in specific neuropsychiatric functional systems. Already, genetic linkage studies have identified 10 regions of the human genome that carry with it susceptibility to development of bipolar disorder (Berrittini 2006). However for such a serious mental illness it is difficult to explain the maintenance of these harmful alleles. One hypothesis would be that atypical co-localization of functions confers on unique individuals enhanced signal-noise ratios in the sequestration of praxis and object-based systems to the left hemisphere. The idea that atypical co-localization of unique combinations of modules in a hemisphere could confer on anomalous individuals emergent properties or an ability is a serious possibility and the idea is not new (Basso et al 1985).

If sequestration of praxis and object-based systems to the left hemisphere enhances the accuracy, as opposed to speed, of motor response then evolutionary mechanisms must have led to the selection for such a trait. Recent studies supporting the existence of both a direct and indirect ventral semantic stream sensitive to semantic paraphasias but not to phonemic paraphasias is congruent with this hypothesis (Duffau et al 2005). Classical lesion studies also have shown that left-sided lesions of the frontal cortex and basal ganglia are apt to cause organic depression whereas euphoria and mania can be triggered by right-sided basal frontotemporal and subcortical damage (Mayberg 2006). These studies to be reviewed suggest any number of combinations of intercommissural inhibition or disinhibition or excitatory mechanisms could be operative.

Moreover, post-injury studies are congruent with the commissural fiber hypothesis that developmentally speaking large scale compensatory modulation of functional neural networks occurs. Similarly, organic depression or mania can result after specific cortical or subcortical lesions. Finally the question must be asked why would such a serious mental illness that is so detrimental persist in the population with such high basal allelic frequencies? Evolutionary hypotheses suggest that low mood could possibly confer adaptive traits under ancestral conditions by increasing the probability of highly realistic assessments pertaining to disengagement or flexibility from salient goal objectives of an individual in rapidly changing environments. This valuation and re-valuation of goals and sub-goal structures will be reviewed here in terms of functional neuroanatomy.

These neuropsychologic and evolutionary studies suggest that for some subtypes of bipolar disorder the functional neuroanatomic organizational principles of the cerebral cortex could function quite differently. Moreover, these distinct patterns of cortical organization in susceptible individuals might be particularly apt to benefit the accuracy of semantic-motor associations, which confer adaptive motor performance, yet also might increase the prevalence of the frequency of deleterious mood-instability traits in kinship groups. In other words, some individuals with certain variants of bipolar disorder would be expected to 
possess atypical, beneficial, highly developed, selected for cognitive abilities (eg, writing, artistic aptitude or creativity) that could explain the maintenance of highly deleterious endophenotypes which reduce life-expectancy at the single subject level.

\section{Bipolar disorder, corpus callosum, and diffusion tensor imaging}

It is hypothesized that bipolar disorder subjects have an associated cognitive endophenotype that presumably has evolved through beneficial traits conferred under ancestral conditions (Berrittini 2006). Moreover functional imaging studies have suggested that there are laterality effects in terms of the localization of the functional neuroanatomical substrates of mood homeostatic mechanisms in bipolar disorder patients (Mayberg 2006). Also early comprehensive studies of atypically cognitively localized subjects were viewed as essential in understanding the deep principles by which language is represented in the brain (Basso et al 1985). The same hypothesis would also hold true for atypically localized bipolar disorder subjects. Finally if the processing of language attributes such as concreteness and abstractness of words is lateralized (Binder et al 2005), and atypically localized subjects thus have different patterns of localization of modules (Singer 2004; Knecht et al 2003) then differences in anatomical structures such as the callosum could canalize the development of atypical white matter tracts in anomalous individuals (Clarke and Zaidel 1994; Goebel et al 2004; Duffau et al 2005). Hence we will review recent diffusion tensor imaging studies in bipolar disorder patients to show evidence of how the specific canalization of white matter tracts occurs with development.

Thirty-three bipolar disorder subjects were compared with 40 normal healthy age, gender, SES and ethnicity matched cohorts. Age and gender were found to be nonsignificant covariates for fractional anisotropy (FA) and were dropped from further analysis (Wang et al 2008). Fractional anisotropy is a measure of the degree to which white matter fibers in the human brain are aligned in a specific direction within a three-dimensional space in the cerebral cortex. There were no significant correlations between clinical factors with the bipolar disorder groups and FA (eg, rapidity of cycling, mood state, medication status, history of substance abuse or co-morbidities). Only $9 \%$ or 3 subjects had co-morbidities and thus for all intents and purposes this was an undifferentiated bipolar disorder sample. FA was lowest in the mid-body of the corpus callosum in bipolar subjects, compared to normal subjects $(\mathrm{p}<0.001)$ and also significantly lower in the genu in bipolar subjects; although of an order of magnitude less $(\mathrm{p}<0.01)$. When average FA values were examined in the mid-body of the corpus callosum bipolar subjects's FA values were approximately $(\mathrm{FA}=0.4)$. In healthy subjects, in the anterior or posterior regions of the corpus callosum FA values were approximately 0.5 . This suggests that most of the variance in FA was occurring within the mid-body of the corpus callosum.

Recent studies have suggested that subcortical hyperintensities are not found in all bipolar disorder subjects, nor are prevalences or severity of these focal white matter lesions significantly different from that of healthy subjects (Strakowski et al 1993). This implies that callosal abnormalities may figure more prominently in these mood disorders (Yurgelun-Todd et al 2007). Incidentally, there was significantly higher fractional anisotropy in bipolar disorder subjects in the medial aspect of the genu compared to normal controls in spite of the small sample size (effect size $=0.48$ ). Of note was that normal healthy subjects demonstrated higher axonal integrity in the splenium compared with the genu whereas the bipolar patients showed similar FA values across both areas. Hence, region of interest and voxel-based comparisons of diffusion tensor studies of bipolar disorder subjects have been confusing with some studies showing higher or lower FA values in the anterior cingulate dependent on specific methodology or statistic used.

Moreover, the splenium has been shown to possess larger diameter axonal fibers and less unmyelinated small diameter fibers than the genu (Aboitiz et al 1992) which could account for this anterior-posterior dichotomy. However, there is controversy over whether these differences are artifacts of relatively greater connectivity within frontal lobes (eg, oblique fibers) in the FA matrix (Purves and Seltzer 1986) compared with the splenium, or whether these differences are a result of composition of regional fibers. Fibers oblique to the $\mathrm{x}, \mathrm{y}, \mathrm{z}$ directions would appear as decreased FA values denoting less white matter when in actual fact these oblique fibers could be more dense than fibers in the $\mathrm{x}, \mathrm{y}, \mathrm{z}$ direction. The white matter underlying the frontal lobes is notoriously heterogeneous in terms of the directions in which fibers are orientated due to the highly top-down and distributed nature of the connections within virtually all areas of the cortex throughout the brain (Denes and Pizzamiglio 1999). Finally, in the Yurgelun-Todd study there was no effect for white matter hyperintensities; that is, only 1 of the 11 bipolar subjects displayed even 1 hyperintensity. When this subject was removed from the analysis, observed differences between patients and controls persisted in the genu (Yurgelun-Todd et al 2007). 
Another study of bipolar disorder subjects demonstrated significantly less fractional anisotropy in the anterior cingulate ( $p=0.003)$ in the largest sample to date (Wang et al 2008). However the clinical value of this finding is questionable. The actual magnitude of the difference indicated that bipolar disorder subjects had only $7 \%$ lesser FA values than their normal counterparts in the anterior cingulum. In the posterior cingulum no significant FA difference levels were found between groups. However there were small absolute levels of differences between groups in the posterior cingulate measurements.

Therefore, for white matter tracts the important factor may well be functional connectivity (Goebel et al 2004) and it does not seem likely that small FA differences would on the whole lead to reduced functionality. This is because anterior and posterior cingulum FA value differences were of the same magnitude and basal levels of FA were within the same range. Moreover, absolute FA values in the anterior cingulum are fraught with measurement idosyncrasies since many oblique fibers are present and automated tractography vectoring was not used. Indeed, asymmetrical white matter connectivity has been recently demonstrated in a DTI tractography study by Houenou and colleagues (2007), implying that careful consideration of micro- and macrostructural white matter asymmetries may be important for group and single-case analysis.

\section{White matter diffusion tensor imaging tractography}

Of unique interest in terms of the neuroanatomical basis of the disorder was the finding by Houenou and colleagues (2007) that only in bipolar disorder patients was the left subgenual cingulate (SC) and amygdalo-hippocampal (AH) complex hyperconnected. That is, a leftward asymmetry was observed with respect to the number of reconstructed fibers between the SC and AH [t(15) $=-3.27, p=0.05]$. The authors speculated that this connectivity most probably represented the uncinate fasciculus since that is the most important connection between the temporal pole and the ventral prefrontal or orbitofrontal cortex (Ebeling and von Cramon 1992), innervating central nuclei of the amygdala with the orbitofrontal regions. In addition, this leftward asymmetry was manifested in a twofold increase in the volume of the left unicinate fasiculus in bipolar disorder patients compared with normal healthy controls $[\mathrm{t}(30)=-2.73, \mathrm{p}=0.01]$. Since both numbers of fibers and volume of fibers was significant implies that Houenou's tractography study is suggestive of a trend. Recall that the number of fibers and the volume of a white matter tract and its function are dependent on the: (i) diameter of axons within a tract; (ii) the proportion of small, medium, and large axons, (iii) the specific intrahemispheric or commissural tract in question which vary in fiber composition and thus density (Clarke and Zaidel 1994; Aboitiz et al 1992; Purves and Seltzer 1986; Denes and Pizzamiglio 1999).

The findings of reduced white matter density in the subgenual regions of the cingulate and frontal white matter give rise to another line of inquiry (Wang et al 2008). Perhaps the reduced diffuse anisotropy in the frontal lobes is a consequence of localized left uncinate hyper-connectivity; assuming that total white matter in an individual brain stays somewhat constant. Moreover, distributions relating to the number of reconstructed fibers normalized for seed mask volume between the left subgenual cingulate and hippocampus/amygdala was twice to fourfold greater in bipolar subjects compared to healthy controls (Figure 1). This potential difference in number of fibers and thickness of this tract suggests that it is functional and not an anatomical artifact. These findings of uncinate hyperconnectivity are in contrast to specific studies showing reduced fractional anisotropy of the fasciculus in schizophrenia patients suggesting a fundamental distinction in etiology between the two disorders (Kubicki et al 2002).

\section{Validity of diffusion tensor imaging ROI approaches?}

Jones and colleagues conducted a technical and methodological study of diffusion tensor imaging (DTI) white matter tract characteristics and of tractography using schizophrenia patients with known anatomical abnormalities (Jones et al 2006). The results highlight a number of limitations with voxel-based mapping and region of interest approaches using DTI. Among the methodological findings was that age was a significant covariate which if not incorporated into the analysis could skew the results in favor of higher or lower FA and mean diffusivity values in the patient groups. The age-specific effects on fractional anisotropy and mean diffusivity have been previously found in a well-defined cognitive skill (reading) with characteristic developmental peaks and plateaus in performance indices (Beaulieu et al 2004; Snook et al 2004). DTI studies must use age as a covariate in developmental or neuropathologic studies; many previous DTI studies have not used such an approach. However, as the authors of this study note there are some problems with DTI studies of fractional anisotropy and mean diffusivity using only region of interest (ROI) or voxel-based mapping; although it must be kept in mind that 

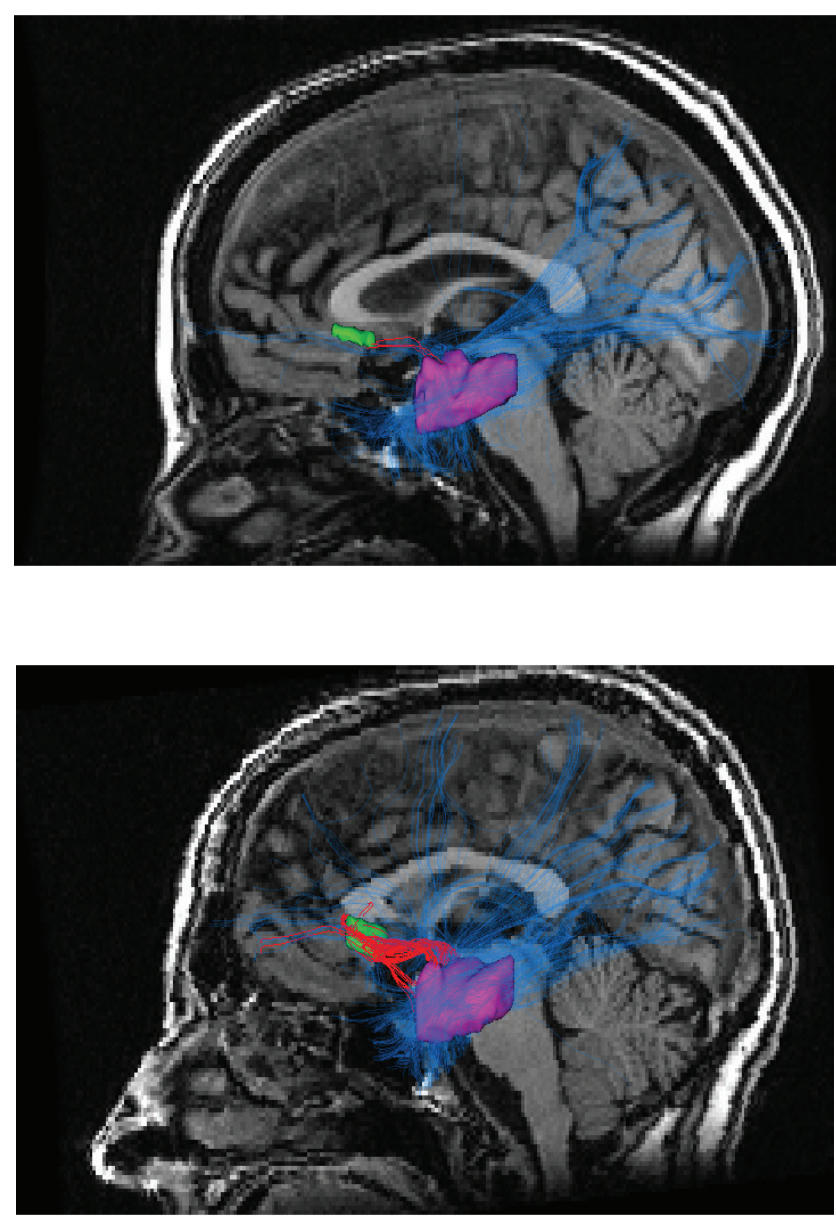

Figure I In the top picture is the diffusion tensor imaging tractography output for a healthy control. In the bottom picture is a representative tractography output from a bipolar disorder patient. All patients were on lithium monotherapy or combined therapy consisting of lithium, atypical neuroleptics and selective serotonin reuptake inhibitors. The bipolar disorder sample consisted of 8 males and 8 females with a mean age of $4 \mathrm{l}$ years. Note the much greater density and thickness of the red colored fibers in the bipolar disorder subjects in the bottom picture.The red tortuous pathway consists of reconstructed fibers connecting the left subgenual cingulate which is depicted in green and the left amygdalo-hippocampal complex depicted in purple. The blue lines represent reconstructed fibers connecting the left amygdalohippocampal complex to the rest of the brain. Copyright (c) 2007, Nature Publishing Group. Reproduced with permission from Houenou J, Wessa M, Douaud G, et al. 2007. Increased white matter connectivity in euthymic bipolar patients: Diffusion tensor tractography between the subgenual cingulate and the amygdalo-hippocampal complex. Mol Psychiatry, I2:1001-10.

the best course of action is for DTI experimenters to use the method which is most congruent with the goals of the study (Wang et al 2008).

In the face of criticism regarding the weaknesses in region of interest or voxel-based mapping of diffusion tensor imaging within a single plane, some of the originators of the technique of DTI advocated for the superiority of diffusion tensor tractography. These experts noted that “...compared to the conventional approach of taking measurements from manually drawn ROIs, our method [DTI-MRI-tractography] presents several advantages: (1) it allows us to investigate specific tracts that are hypothesized to be involved in the pathogenesis of [the disorder in question]; (2) it provides data from the entire tract rather than from a limited portion of it; and (3) it is less prone to operator-induced bias..." (Jones et al 2006, p. 235). In sum, experts in the use of diffusion tensor imaging have shown that in a specific clinical sample of neuropsychiatric patients diffusion tensor imaging magnetic resonance tractography possesses clinical research potential. It is only a matter of time before such rich sources of qualitative information are readily and widely available to the neuroradiologist, behavioral neurologist, and cognitive neuropsychologist.

When tractography and region of interest or volume of interest methods were compared, the hypothesis that tractography could provide unique information was borne out in the Houenou and colleagues (2007) study. It was found that fibers between the pons and the cerebellum belonging to the cerebellar peduncle were successfully reconstructed, whereas nonexistent fibers between the subgenual cingulate and the pons were not reconstructed. A recent theoretical review of the topic by specialists made several compelling arguments for the use of tractography over DTI regions of interest analysis (Kanaan et al 2006).

Kanaan and colleagues (2006) used a novel quantitative diffusion tensor tracking algorithm which differed from Houenou's diffusion tensor deflection method in a number of ways. Kanaan's method was verified in schizophrenia patients and compared with both region of interest and voxel-based analysis. It has a number of advantages over DTI-deflection in that (i) principal orientations of the diffusion tensor uses an automated B-spline-interpolated continuous tensor field, (ii) the fibers were tracked in both directions, and finally (iii) these reconstructed fibers were compared for neuroanatomic accuracy by comparison with in-house MATLAB visualization scripts and neuroanatomic atlases. The highly experienced London Institute of Psychiatry DTI group have thus developed an important method for improving the tractography method and therefore the Houenou tractography findings are provocative but require replication using different methodologies and across laboratories. That said it is important to mention that the Houneou findings show some signs of reliability and validity since single subject maps showed significant cross-subject agreement.

These authors noted conceptual and practical difficulty with ROI and voxel-based mapping including difficulties in replication across methods, high variability in white matter tracts and lack of standard anatomical references. The authors speculated that contradictory findings with 
respects to ADC, (apparent diffusion coefficient or rate of speed of diffusion) and FA in frontal white matter could be entirely artifactual and that the true gold-standard for connectivity analysis may be individualized and group DTI tractography analysis. It seems tentatively then that the subgenual cingulate - amygdalo - hippocampal connections are a reliable finding and can explain many associated symptoms of bipolar disorder. However it is unclear what the functional correlates of such hyperconnected white matter tracts are.

\section{The discovery of a ventral semantic stream}

Are there dual routes to language as in the visual system? Electrocortical and subcortical stimulation studies suggest a dorsal phonological route and ventral semantic stream coursing from the anterior temporal lobe to the frontobasal region (Mandonnet et al 2007). Intraoperative direct stimulation was used by the investigators to confirm anatomofunctional correlations at cortical and subcortical levels in patients undergoing left temporal pole gliomas. It is important to mention that aside from the glioma, there was no reason to suspect that subjects had any atypical patterns of white matter connectivity. Indeed, Catani and ffytche (2005) have provided maps, depicted in Figure 2 below, of the ventral stream semantic pathways in normal healthy human subjects. If the inferior occipitofrontal and the inferior longitudinal fasciculus are essential pathways in the ventral semantic stream, then an understanding of temporal pole functions which are connected to the ventral prefrontal cortex directly and indirectly by the uncinate fasciculus will be required.
Cortical - subcortical stimulation was carried out in 17 glioma patients. These presurgical mapping studies provided evidence in favor of the existence of a main pathway underlying the semantic system located in the left hemisphere (Duffau et al 2005). This pathway joins the posterior and superior temporal areas with the inferior and dorsolateral prefrontal cortex and is identified as the inferior frontooccipital fasciculus. The fasciculus narrows at the junction of the frontal and temporal lobes and passes through the anterior floor of the external capsule with terminal radiations reaching the middle and inferior temporal gyri as well as all the way to lingual and fusiform gyri. Electrostimulations anywhere along the route in the superficial white matter underlying cortical areas or in deep subcortical nuclei resulted in semantic paraphasias. Due to the density of mappings, the accuracy of magnetic resonance imaging (MRI) guided point locations with the aid of human brain atlases, and the elicitation of nonsemantic paraphasias (eg, phonemic paraphasias) in deviations off this route, the authors named this fasciculus a de facto "semantic loop".

Vigneau and colleagues (2006) in their review of 129 phonology, sentential or semantic processing neuroimaging studies published between 1992 and 2004, postulated that the temporal pole and the anterior portion of the fusiform gyrus were part of a semantic network that was in part instantiated by the inferior longitudinal fasciculus. This fasciculus is also known as the occipitotemporal fasciculus, which links the posterior inferior temporal region with the temporal pole. Refined semantic information was then hypothesized to be relayed by the temporal pole through the uncinate fasciculus on through to the orbitofrontal cortex.
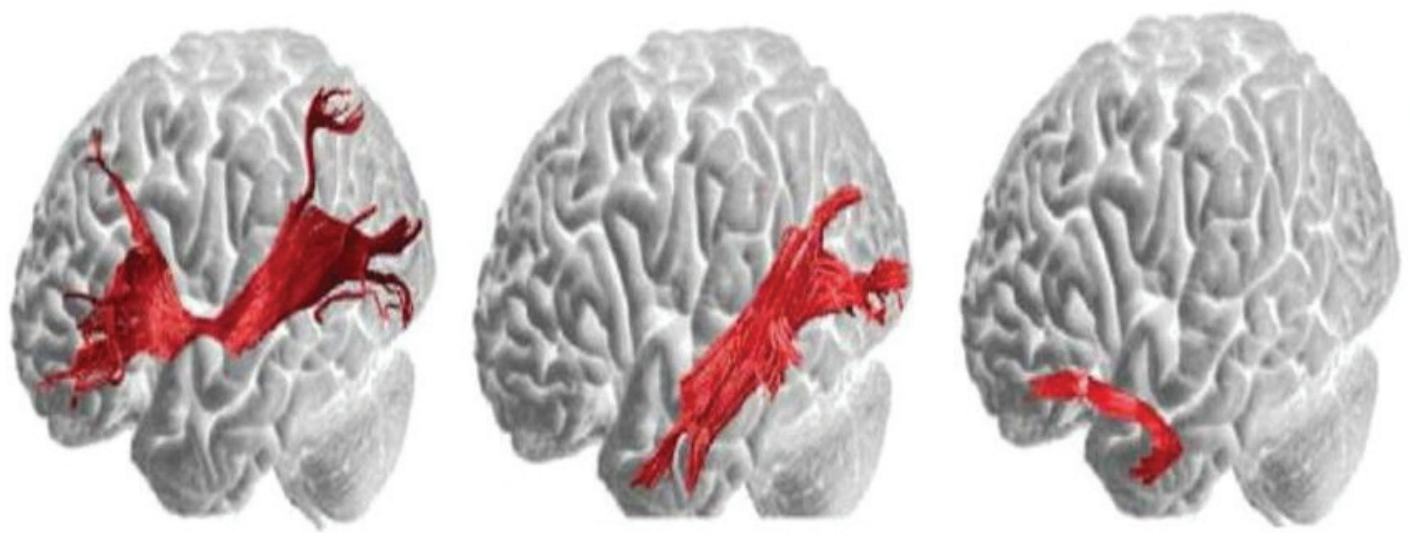

Figure 2 Left illustration depicts the direct pathway from the posterior cortices to the prefrontal cortex. The inferior occipitofrontal fasciculus connects the posterior temporal areas and the orbital and lateral prefrontal regions. Middle illustration consists of the first segment of the indirect pathway. The inferior longitudinal fasciculus links the posterior occipitotemporal regions with the temporal pole and this fiber tract courses underneath the inferior occipitofrontal fasciculus. Right illustration depicts the second component of the indirect pathway. The uncinate fasciculus connects the anterior and medial temporal lobe with the orbitofrontal regions. Copyright $(C) 2005$, Oxford University Press. Adapted with permission from Catani M, ffytche DH. 2005. The rises and falls of disconnection syndromes. Brain, I28:2224-39. 
The inferior longitudinal fasciculus (ILF) runs laterally and inferiorly to the lateral wall of the temporal horn whereas the inferior occiptofrontal fasciculus runs just medial of the ILF and above the optic pathways. Speculation and controversy arose about whether the indirect fiber pathway between the inferior-posterior occiptotemporal region and the temporal pole consisted of straight line fibers or consecutive U-shaped fiber junctions (Tusa and Ungerleider 1985). Diffusion tensor imaging tractography studies of the human occipitotemporal lobe have since confirmed that both straight line fibers and looping U-shaped fibers are present, thereby conferring in the ILF a potential fast and slow computational route.

Although stimulation of the inferior occipitofrontal fasciculus did result in reliable semantic paraphasias, electrical stimulation of the inferior longitudinal fasciculus did not induce any naming disturbances; nor did resection of a portion of it cause language problems (Mandonnet et al 2007). However, the authors note that lack of an effect for resection or stimulation does not mean that the ILF is not involved in semantics; due to plasticity from slow-growing lesions the functions could conceivably be redistributed within the ipsilateral hemisphere or contralateral homotypic regions (Heilman and Valenstein 2003). On the basis of their electrostimulation findings, the investigators hypothesized that there were two pathways constituting a ventral semantic stream (Mandonnet et al 2007). A direct dominant pathway consisting of the occipitofrontal fasciculus connecting posterior temporal regions and the prefrontal cortex; as well as an indirect pathway consisting of the inferior longitudinal fasciculus (posterior occipitotemporal $\rightarrow$ temporal pole $\rightarrow$ uncinate fasciculus $\rightarrow$ orbitofrontal cortex). Finally, Duffau (2008) makes the interesting observation that at the level of sentence comprehension the inferior direct occipitofrontal fasciculus has been found to make links with phonology and linguistic comprehension units, implying a role for this ventral semantic stream in language acquisition and development (Sakai 2005).

\section{Functional neuroanatomy of the temporal pole}

Arnold and colleagues (1994) showed that neuropathological changes to the temporal pole occur in Alzheimer's and Pick's disease, and Braak and colleagues (1993) demonstrated that during the initial stages of Alzheimer's, the temporal pole is among the first regions to show neurofibrillary tangles. Episodic memory impairments are considered among the earliest symptoms of the onset of Alzheimer's disease (Bassett et al 2006) which is congruent with the functions of the temporopolar cortex (Nakamura and Kubota 1996). Cholinergic modulation of the anterior temporal pole could play an essential role in its functions, since Flynn and Mash (1986) reported that the affinity and concentration of nicotinic acetylcholine receptors was decreased in this region in Alzheimer's disease patients. Like electrical stimulation of the medial temporal lobe, recent electrophysiological studies have shown that electrical stimulation of the anterior ventromedial temporal lobe can also result in the generation of simple or complex seizures (Munari et al 1993).

In Figure 3 (on the next page), the ventral temporopolar cortex is represented by $\mathrm{TPv}$ and the perirhinal cortex is comprised of Brodmann's area 35 and 36. Damage to the ventral temporal pole produces loss of memory for familiar objects or associative agnosia but not apperceptive agnosia, suggesting that the resemblance of objects including faces associated with personal recollective memory, is bound here. TEO is involved in the construction of singular objects and TE is critical for visual recognition and memory of objects, whereas V4 is involved in color perception. TH and TF appear to be related to spatial and tactual function and together are sometimes referred to as the parahippocampal cortex involved in place learning.

Brodmann's area 7 is the superior parietal lobe involved in spatial location memory encoding and STP refers to the superior temporal polysensory area which runs posterior to anterior and is involved in complex auditory and spatial processing. TPd is the dorsal temporal pole and is involved in auditory spatial object construction with the superior temporal gyrus usually associated with Wernicke's area language comprehension functions. The anterior and posterior entorhinal cortex provides the major route for information into the hippocampus. Interestingly, the temporal pole does not receive direct innervation from the prefrontal cortex, but rather dorsal routes are through the parahippocampal cortex and ventral routes are through the perirhinal cortex involved in recognition memory.

\section{Temporal pole and theory of mind}

The temporal pole (TP) receives projections from three sensory systems within the temporal lobe proper. The dorsolateral TP receives projections from the third-order auditory association cortex whereas the ventral TP receives projections from the extrastriate cortex at the terminal end of the occipitotemporal cortex (Olson et al 2007). An important role for the medial aspect of the temporal pole has been found in the awareness of internal somatic states through afferents received from the insula (Critchley 2004). 


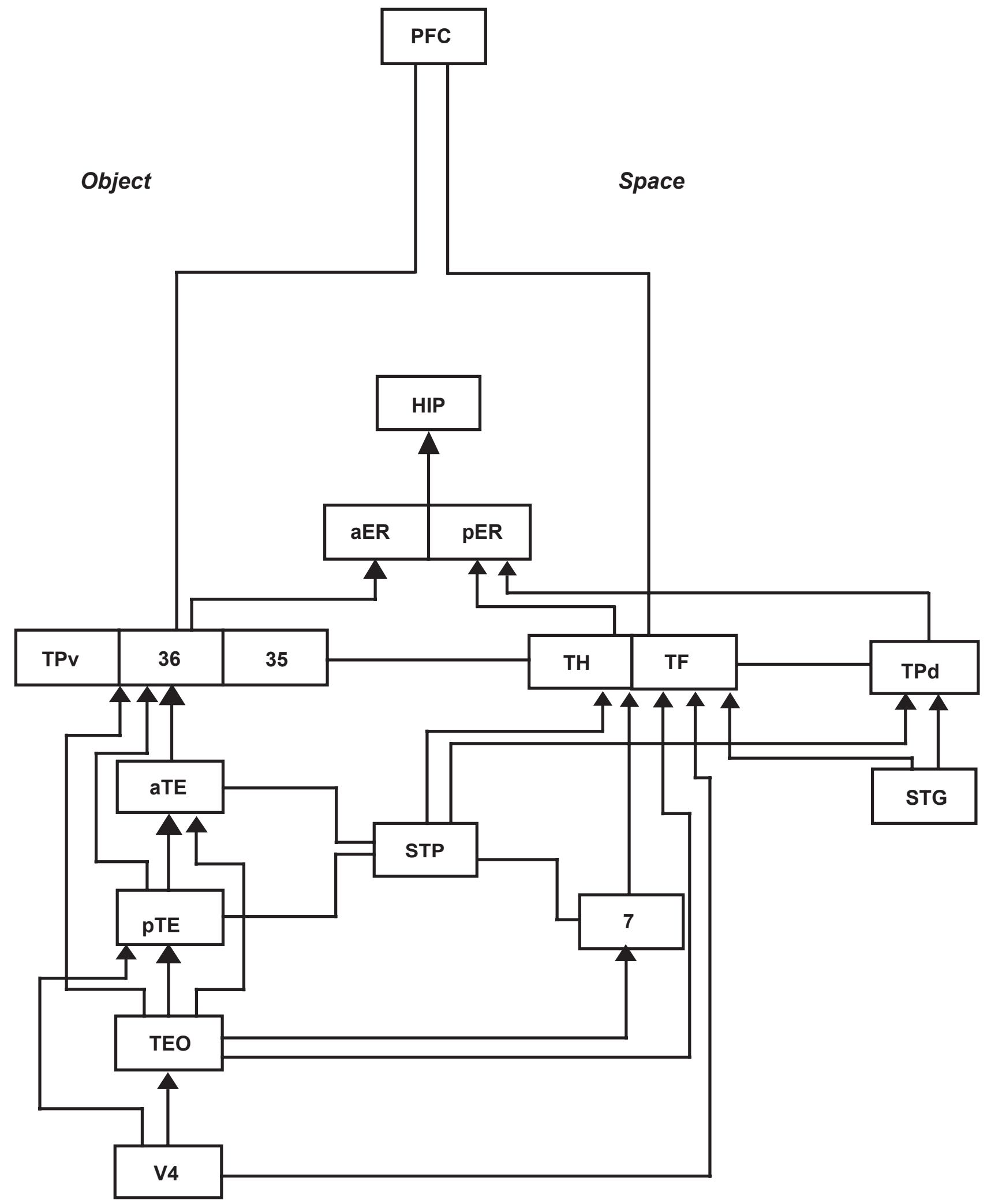

Figure 3 Copyright () 1996, Elsevier. Adapted with permission from Nakamura K, Kubota K. 1996. The primate temporal pole: Its putative role in object recognition and memory. Behav Brain Res, 77:53-77.

Abbreviations: HIP, hippocampus; PFC, prefrontal cortex;TPv, the ventral temporopolar cortex;TPd, the dorsal temporopolar cortex; aER, anterior entorhinal cortex; pER, posterior entorhinal cortex; aTE, anterior area TE; PTE, posterior area TE; TE Brodmann's areas 20 and 21 ; TH \& TF are cortical areas at the posterior end of the temporal lobe and are often referred to a parahippocampal cortex; STG, superior temporal gyrus; STP, superior temporal polysensory area; 7, superior parietal lobule; 35 and 36 are known as the perirhinal cortex. 
Some of the most interesting studies to date on the temporal pole function have had to do with the organic induction of rapidly vacillating mood states with TP damage. Murai and Fujimoto (2003) found that brain injury to the TP resulted in rapidly cycling bipolar disorder and Glosser and colleagues (2000) established that anterior temporal resections, especially within the right lobe were apt to produce depression, anxiety, and organic mood disorder.

Three separate reports, as noted by Olson, have found that anterior temporal pole damage can cause acquired bipolar disorder (Jorge et al 1993; Brooks and Hobyln 2005; Carran et al 2003). Finally, Olson and colleagues (2007, p. 1720) argue that based on reviews of studies of Kluver-Bucy syndrome in monkeys and man, that TP regions are instrumental in supporting group social behaviors such as the tendency to band together to form societies, to participate in family life and to interact with others in their respective social groups (Olson et al 2007). Another ubiquitous finding pertaining to the anterior temporal poles are its involvement with high level face processing, such that perceptual recognition of faces is intact, yet there is impaired multimodal recognition of faces.

Barton and colleagues $(2001,2004)$ have shown that associative prosopagnosia may occur independent of the integrity of memory functions, and that face priming across modalities may be ineffectual with patients with anterior temporal lobe damage. The anterior temporal lobes appear critical then to linking person-specific memories to the structural description of a face and such multi-modal deficits have extended to deficits in recognition by voice (Gainotti et al 2003) name of person (Snowden et al 2004), or handwriting (Gentileschi et al 2001). This is analogous to loss of access to person-specific knowledge which is a type of high-level semantic deficit. Olson and colleagues (2007) noted that over 19 studies have found reliable temporal polar activation with theory of mind tasks in which another's thoughts or beliefs must be inferred (Fletcher et al 1995a; Goel et al 1995; Baron-Cohen et al 1999; Brunet et al 2000; Castelli et al 2000; Gallagher et al 2000; Vogeley et al 2001; Berthoz et al 2002; Ferstl and von Cramon 2002; Gallagher et al 2002; Calarge et al 2003; Sehultz et al 2003; German et al 2004; Iacoboni et al 2004; Ohnishi et al 2004; Walter et al 2004; Mitchell et al 2006; Saxe and Powell 2006). Similar types of tasks also have resulted in reliable temporal polar activation. Detection of deception, moral decision making, inference of the emotional state of others, and ratings of how much one feels the negative emotions of others also resulted in polar activation (Olson et al 2007). Some groups have concluded that the temporal polar regions are inextricably linked with mentalizing and that this region is a key element in a general neural network involved in making mental state attributions about the actions of others (Frith 2001; Frith and Frith 2003; Vollm et al 2006).

A primary function of the anterior temporal poles then is to associate either the visual ventral temporopolar region, or the auditory dorsal temporopolar region, with visceral emotional responses to facilitate the "...storage of perception-emotion linkages forming the basis of a personal semantic memory...(p. 1725) (Olson et al 2007). There also appears to be some evidence that the temporal polar regions are important for attachment processes, since bilateral TP lesions induce loss of normal emotional attachment in mother monkeys to their infants and to peer monkeys (Kling et al 1976). It is possible that propositional knowledge pertaining to the self and others is bound in the temporal pole, and is imbued with emotional connections via proximity with the amygdala-hippocampal complex, resulting in emergent properties of attachment, personal semantic memory and attendant formation of social groups.

\section{Temporal pole and narrative}

In ten separate studies involved in basic semantic processes associated with narrative the temporal pole has been shown to be reliably activated (Duffau 2008). These include categorical decisions pertaining to the living versus nonliving character of visually presented words and pictures (Bright et al 2004) or retrieval of a word associated with an intransitive gesture (Damasio et al 2001). James and Gauthier (2004) found that retrieval of previously learned semantic features of a novel object reliably activated the temporopolar cortex, and Noppeney and Price (2004) similarly made this discovery when subjects were visually presented with abstract word triads and had to choose which of the two words were most alike.

Visual presentation of four different categories of words (Perani et al 1999), passive listening to words (Price et al 1996) or visual presentation of single nouns and judgements as to whether the noun could apply to a human being or not (Scott et al 2003), all activated TP. An n-back task requiring subjects to determine if the current object is the same as the previously displayed object (Sevostianov et al 2002), and a semantic association task requiring subjects to match word and picture triplets of the same category for meaning (Vandenbergh et al 1996), both resulted in a TP signal. In sum, high-level objectorientated actions imbued with abstract categorical semantics were particularly apt to activate the TP; particularly in PET 
studies where signal fade-out due to inhomogeneity artifacts were not likely to skew the results.

More specifically, Duffau (2008) reviewed studies directly implicating the TP in the integration of a coherent narrative structure. When subjects judged the plausibility of metaphors or sentences (Bottini et al 1994), or when they read stories (Fletcher et al 1995b), read sentences (Stowe et al 1998), or were simply listening to intelligible semantic content (Scott et al 2000), the TP was activated in every instance. If subjects were required to integrate the content of a sentence such that lexical decisions were made on sentences ending with an expected versus unexpected word, a temporopolar region signal resulted (Baumgaertner et al 2002). Passive listening to stories, or tasks requiring participants to provide the number of narrators in different stories (Crinion et al 2003), or reading a text in a nonnative language (Vingerhoets et al 2003), all resulted in foci in the TP. Attending to a speaker's voice (von Kriegstein et al 2003), or judging the syntactic or semantic plausibility of Chinese or English sentences resulted in reliable activation in TP (Luke et al 2002).

In a recent study listening to narrative texts activated the posterior-anterior extent of the left superior temporal sulcus as far forward as the temporal pole (Crinion et al 2006), and critically a Wernicke's area lesion also impaired anterior left temporal lobe function. The implication is that clinical studies of language in stroke patients have underestimated the role of the left anterior temporal pole in comprehension of narrative speech since routinely only lesion studies have been carried out on these patients and only a functional neuroimaging study could demonstrate such a "virtual lesion". Passages of prose were read twice to subjects during successive scans with the requirement to remember them. Narratives consisted of either standard readily comprehensible stories or unusual stories for which the global theme was difficult to extract. Mental frameworks for understanding the stories were provided in the form of relevant, irrelevant or no visual cues. Maguire and colleagues (1999) found that both the medial ventral orbitofrontal cortex and the left anterior temporal pole were associated with general processes of comprehension of the narratives, with accompanying mental templates for understanding (Maguire et al 1999).

\section{Orbitofrontal cortex connectivity}

In their influential review of the functional neuroanatomy of the orbital frontal cortex Zald and Kim (1996) note that this "nose-brain" could be derived from two ancestral lines of cortex. They postulated that an archicortex moiety arose from ancient hippocampal formation structures involved in spatial localization, and that a paleocortex moiety evolved from a primitive olfactory core responsible for identifying objects. Early single-cell stimulation monkey studies showed that neurons within the orbital frontal cortex had receptive fields which were bilateral, exhibited azimuthal sensitivity and were sensitive to moving stimuli. Many of these stimuli were either excited or inhibited by auditory sounds such that for both vision and audition a variety of on and off effects was found. Some of these cells showed audiovisual interaction presumably due to convergence at the cortical cell level. In one example, an auditory stimulus of a characteristic frequency had a powerful inhibitory effect on many neurons and this inhibitory effect was found to negate the excitation caused by a simultaneous visual stimulus (Benevento et al 1997). Subsequently it was shown that both complex patterns and objects can elicit such effects in the orbitofrontal cortex (Wilson et al 1993).

There appears to be one functional cortical zone within this transitional region and it is comprised of three key regions: the temporal pole, insula, and orbitofrontal cortex (Morecraft et al 1992). The mediodorsal nucleus of the thalamus is the primary source of thalamic innervation of the orbitofrontal cortex (Ray and Price 1993). In addition to the direct connection between the mediodorsal (MD) nucleus and the orbitofrontal cortex, there are seven separate indirect pathways from MD to [substrate $\mathrm{x}$ ] to orbitofrontal cortex. These intermediaries through the indirect pathway include the amygdala, primary olfactory cortex, entorhinal cortex, perirhinal cortex, temporal pole, superior temporal gyrus, inferior temporal gyrus and the insula. It is hypothesized that the direct route carries detailed perceptual information whereas projections through the MD possess more integrated refined and multimodal information. Little known is that the orbitofrontal cortex is the only region that possesses a strong association with the amygdala. The lateral nucleus of the amygdala is a crucial weigh station for sensory input and the central nucleus is a source of major input into the brain stem and hypothalamic structures. Collectively, these amygdalic structures control species-specific survival responses coordinated with endocrine, autonomic and involuntary behavioral action correlates (Davis 1992).

A critical and often overlooked point is that of how the prefrontal cortex exerts control over the hippocampal formation and associated structures. The only major prefrontal afferent to the hippocampal area is from the orbitofrontal cortex to the entorhinal cortex (EC), and although the EC is intimately connected with the hippocampus the orbitofrontal cortex does not possess direct connections with 
the hippocampus (Van Hoesen et al 1975). This suggests a terminal pathway ultimately meeting at the orbitofrontal cortex site of modulation for all prefrontally-mediated alterations of mnemonic functions associated with the medial temporal lobe. Finally, dense projections from the medial and lateral orbitofrontal cortex and gyrus rectus reach the lateral hypothalamus - one of the major output pathways of the limbic system (Johnson et al 1968). The orbitofrontal cortex has direct projections with the frontal eye fields and dorsolateral prefrontal cortex such that visual search and working memory also can be influenced by the value of stimuli (Morecraft et al 1992).

Five distinct types of basal ganglia-thalamocortical circuits have been described and the lateral orbitofrontal circuit is most relevant to an understanding of the basal ganglia-cortical loops (Figure 4) (Alexander et al 1986). By way of example, bilateral lesions of the lateral orbitofrontal area, and/or lesions to the caudate nucleus to which the lateral orbitofrontal afferents fibers project, will result in perseverative interference with a monkey's capacity to make appropriate switches in behavioral set (Divac and Manning et al 1967;
Mishkin et al 1978). Hence an essential function of the basal ganglia is to integrate the sensory input arriving from the neocortex with contextually appropriate motor or cognitive functioning programs. The striatum sends projections to the globus pallidus and the substantia nigra. The direct striatal-globus pallidus/substantia nigra pathway inhibits the globus pallidus/substantia nigra output nuclei and thus causes disinihibition of the thalamus. Activation of the direct loop facilitates the triggering of programs at the cortical level through double inhibition. Discrete portions of the mediodorsal nucleus of the thalamus are important in emotional and cognitive functioning through their connections with the orbitofrontal and dorsolateral prefrontal cortex, respectively (Goldman-Rakic and Porrino 1985). Lesions to this feedback system can result in disinhibition of emotional circuits leading to depression, mania and/ or obsessive compulsive disorder (Chamberlain et al 2005).

Figure 5 shows how the medial orbitofrontal loop follows a unidirectional course thereby allowing affectively valued stimuli to influence motor programs via the basal ganglia. Recall that affective valuation is different from affective

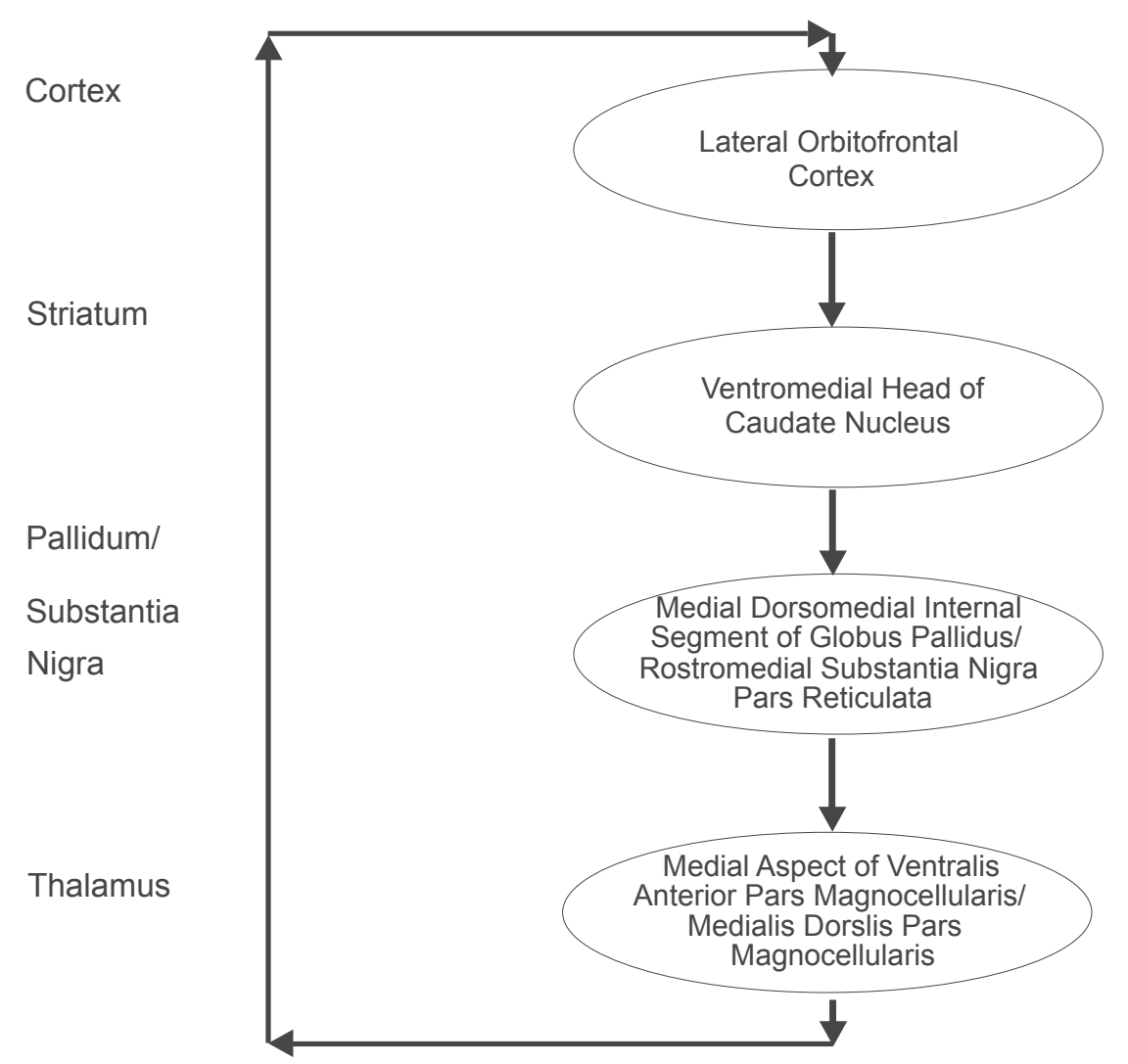

Figure 4 The lateral orbitofrontal basal ganglia-thalamocortical circuit. The ventromedial head of the caudate nucleus receives input from the superior temporal gyrus, the inferior temporal gyrus and the anterior cingulate area. The closed loop of the lateral orbitofrontal circuit is completed by the return from these two regions of the thalamus to the lateral orbitofrontal cortex. Copyright (c) 1986. Redrawn and adapted from Alexander GE, DeLong MR, Strick PL. 1986. Parallel organization of functionally segregated circuits linking basal ganglia and cortex. Annu Rev Neurosci, 9:357-8I. 


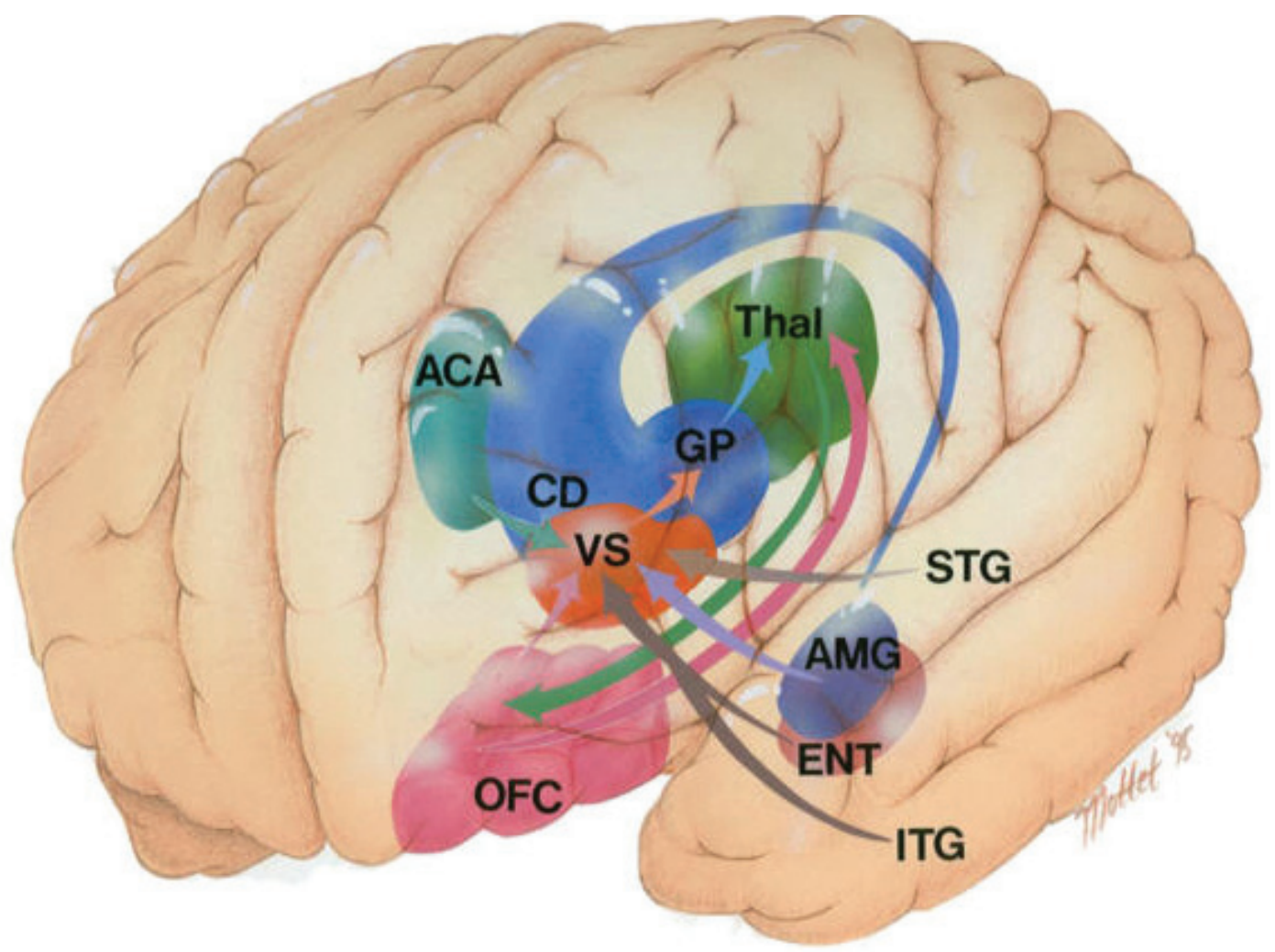

Figure 5 The medial orbitofrontal - basal ganglia loop. Copyright @ 1996, American Psychiatric Publishing. Adapted with permission from Zald DH, Kim SW. I996. Anatomy and function of the orbital frontal cortex. I:Anatomy, neurocircuitry, and obsessive-compulsive disorder.J Neuropsychiatry Clin Neurosci, 8: 125-38.

Abbreviations: ACA, anterior cingulate area (light blue);AMG, amygdale (purple); CD, caudate nucleus (dark blue); ENT, entorhinal cortex (brown); ITG, inferior temporal gyrus; OFC, orbitofrontal cortex (pink); STG, superior temporal gyrus; Thal, thalamus (green); VS, ventral striatum (orange).

valence since valence denotes an instinctual approach or avoidance behavior, whereas valuation can be abstract without stimulus features and connotates instrumental behavior. The interaction of the medial temporal hippocampal - amygdalic structures and the orbitofrontal cortex is of a magnitude greater in terms of complexity than the separate study of either of these regions. Effective and functional connectivity studies using functional MRI may be especially illuminating with respect to the functional neuroanatomy of orbital and temporal pole hyperconnected regions in the bipolar patient. For instance the ventromedial head of the caudate nucleus is the source of afferent fibers emanating from the auditory stream of the superior temporal gyrus, the visual stream of the inferior temporal gyrus and the anterior cingulate gyrus. Connections between these regions allows the imbuement of stimulus-specific value and context-specific determination of reward and hence goal states in the brain.

The medial orbitofrontal cortex (pink) has direct reciprocal connections with the accessory basal amygdala (purple) (Carmichael and Price 1995). The ventromedial temporal pole area 38 is also reciprocally connected with the medial aspect of the orbitofrontal cortex (Carmichael and Price 1995;
Moran et al 1987; Vogt and Pandya 1987). The auditory association areas of the dorsal temporal pole are reciprocally connected with the lateral orbitofrontal cortex (Carmichael and Price 1995; Moran et al 1987; Vogt and Pandya 1987). Finally the lateral orbitofrontal cortex has reciprocal connectivity with the area TE and frontal eye fields; this highlights the OFC control over sensorimotor processing (Carmichael and Price 1995).

\section{Orbitofrontal cortex review}

A neuroeconomical view of the function of the orbitofrontal cortex is that it represents the relative value of potential choices at a reductionistic level (Padoa-Schioppa 2007). Moreover, this view suggests that orbitofrontal cortex neurons encode economic value independently of visuomotor contingencies, consistent with an abstract object-based model rather than one action-based. Lesions of the ventromedial prefrontal cortex often have been associated with reversal learning (Roberts 2006). Reversal learning is exemplified by the Iowa Gambling Task wherein subjects must choose between 4 decks of cards (Bechara et al 1997). On each trial a card is drawn and the subject either wins or is provided 
with a win and a loss. As Fellows $(2005,2007)$ noted two of the decks are associated with large wins but even larger losses and the other two decks are associated with smaller wins but even smaller losses. The second set of decks is the conservative choice or advantageous one. Critically, the order of cards in each deck is fixed so that after large wins on several sets of consecutive trials, (on the disadvantageous decks), large losses begin to accrue. After large losses accrue, healthy and nonorbitally lesioned patients choose spontaneously to change to the advantageous decks, whereas orbitally lesioned patients perseverate on the decks which initially provided large wins.

To demonstrate more generally that the Iowa Gambling Task (IGT) is dependent on reversal learning required an ingenious design change that eliminated the requirement for reversal learning (Fellows and Farah 2005). Two conditions were incorporated into the new design. There was the original IGT and a shuffled version of the IGT in which the cards were shuffled so that there was no opportunity for delayed reversal learning. In the original design, ventromedial lesion patients performed poorly; in the same task where there was no reversal learning switch, they performed normally. Interestingly, the dorsolateral prefrontal lesioned patients performed poorly in both tasks, perhaps as the consequence of generalized working memory impairment. These results show conclusively that difficulties that ventromedial lesion patients exhibit in the study, result not from impaired decision making, but rather from reversal learning as a deficit in flexible reinforcement using knowledge of contingencies. Finally, Fellows (2007) noted that the orbitofrontal cortex also may be involved in a simpler type of task in which the subject must determine the relative value between a number of choices. This preference judgment was found not to correlate with reversal learning, suggesting that the two tasks may rely on different subregions of the orbitofrontal cortex.

\section{Orbitofrontal cortex: Stimuli, rewards, and future actions}

The orbitofrontal cortex is involved in at least five different separate functions. Firstly, the orbitofrontal cortex encodes the value of stimuli as these stimuli are perceived, allowing for goal-weighting and goal/sub-goal structuring. Such valuation encoding allows for long-term and immediate future planning, specifically with respect to reinforcement contingencies. Secondly, the orbitofrontal cortex is involved in maintaining expectations of future reward thereby providing information on specific courses of action or particular stimulus choices. The orbital regions also play an essential role in coordinating error signals with midbrain regions, which could conceivably underlie the learning of reward predictions. The orbital gyri are also involved in encoding the underlying implicit rules or structure of an abstract problem in order to guide predictions of future reward. However such future reward encoding does not constitute decision making per se but rather implicit goal weight structuring or simple logical operator functions. Finally, orbital regions appear to function in computing reward relevant decisions as well as in representing the reinforcement contingencies of a particular decision in association with dorsolateral prefrontal structures (O’Doherty 2007).

O'Doherty (2007) notes that among the main functions of the orbital gyri or orbitofrontal cortex is assisting in making adaptive decisions under conditions of uncertainty, as well as in the face of changing contingencies (O'Doherty 2007; Bechara et al 1994; Rolls et al 1994; Hornak et al 2004). Subsequent studies show that neurons within the orbitofrontal cortex encode the state-dependent reward value of not only intrinsically hedonic olfactory (Anderson et al 2003) and gustatory stimuli (Small et al 2003), but also that of more neutral somatosensory, auditory, and visual stimuli. In this context, the perceptual-emotional associations formed in the anterior temporal pole could be the terminal neural network input upon which the relative valuation orbitofrontal network operates.

The orbitofrontal cortex also has also been shown to respond to secondary reinforcers such as money or social praise (Breiter et al 2001; Elliott et al 1997). However, the orbitofrontal cortex responds not only to rewards but also to aversive stimuli like foul tastes or actual monetary loss in economic games (O'Doherty et al 2001a; O'Doherty et al 2001b). Moreover, there seems to be a medial/lateral parcellation of function across the orbitofrontal cortex. Both O'Doherty and colleagues (2001a) and Ursu and Carter (2005) found that the medial aspects of the orbitofrontal cortex blood flow increased in response to rewards and that lateral aspects of the brain region were found to respond to broad classes of aversive stimuli (Ursu and Carter 2005). Other functional neuroimaging studies have made similar discoveries, suggesting that the medial/lateral distinction might be a general feature of functional organization in the orbitofrontal cortex (O’Doherty 2007).

Similarly, avoidance of an aversive outcome activated the medial orbitofrontal cortex and conversely, failure to obtain a reward activated the lateral orbital surface (Kim et al 2006) suggesting some type of encoding of logical operators within 
the region. At least two studies have shown that anticipation of receipt of rewards or highly aversive stimuli, in association with predictive cues, led to anterior and rostral orbitofrontal cortex activation (O'Doherty et al 2002; Gottfried et al 2002). As with the increasingly abstract future-focused behavior gradiations found within the posterior to anterior temporal lobe, a similar type of anticipatory behavior continuum appears to operate within the orbitofrontal cortex. Finally, distinctions have been made by O'Doherty (2007) between stimulus substitution and signalling predictive mechanisms that could well involve some implicit nonconscious algorithm functions in the orbitofrontal cortex (O'Doherty 2007). The essence of this finding is that it is extremely adaptive for the animal or human organism to have a predictive mechanism that would signal an impending affectively laden event without eliciting a conscious representation of that event.

To always require conscious, rather than unconscious and automatic representations, is computationally cumbersome, inefficient, and slow and therefore maladaptive in life or death situations. This signalling mechanism would in effect allow for the animal to distinguish cues that predict a stimulus from those of the actual unconditioned stimulus (eg, rewarding food versus aversive stimuli). This is because different behavioral responses are elicited when anticipating an event as opposed to immediately experiencing it. As O'Doherty (2007, p. 260) notes if “...stimulus substitution were to be the only mechanism in place then a CS would be indistinguishable from the UCS from the point of view of the animal...". To provide a good example of this, if there was only stimulus substitution and not also predictive signalling then the animal would try to eat the conditioned stimulus (CS) (eg, light) rather the unconditioned stimulus (UCS) (eg, food). The predictive signalling component involves differentiated approach and anticipatory responses to the light as opposed to the undifferentiated approach response and consummatory behavior directed towards the primary reinforcer of food.

Similarly, a CSfor a food reward can involve a behavioral approach, avoidance, or orientation responses, distinct from those produced by the unconditioned stimulus itself. The basic idea is that not all unconditioned responses are identical to those conditioned responses elicited by the primary or secondary reinforcer. Moreover, reflexive responses are tied to second signal systems including semantics, operant responses and procedural learning. Under these circumstances, a motor response conditioned to semantic stimulus is not only possible, it is highly probable. Such preconscious responding enables differentiation of salient
UCS's from exceedingly complex background contexts. Finally, Gottfried and colleagues (2003) found that the anterior orbitofrontal cortex encoded UCS abstracted de-contextualized value rather than the sensory properties of a stimulus per se (Gottfried et al 2003). Related to this delayed de-contextualized encoding of raw value magnitudes, is the finding by Tremblay and Schultz (1999) that orbitofrontal neurons increased in spiking responses during the delay of the expectation of rewards. Hence if bipolar disorder is associated with the enhanced connectivity between anterior temporal pole and orbitofrontal cortex brain regions it is still a requirement to determine what are the functional, behavioral, and cognitive manifestations associated with the illness.

\section{Functional neuroanatomy of bipolar disorder}

Strakowski and colleagues (2005, p. 105) note in their review of the functional neuroanatomy of bipolar disorder that "...structural measurements may not have clear functional correlates...". This statement summarizes the concept of supervenience. Supervenience is a term used to describe a broadly physicalist and nonreductive philosophy of mind. In essence it means that two identical brains states cannot then differ in mental qualities, or conversely that something cannot alter in a mental state without altering in some physical respect. However, the reverse scenario is not necessarily true. In other words, psychological properties can be multiply realized in many physical properties or different brains states (Davidson 2001). Thus, it is the configuration of spatially and temporally discontinuous modules distributed throughout the brain and interacting in concert in real-time, that defines a mental state. A mere structural abnormality does not have the effect of causality. For example, in bipolar disorder, until it can be shown that structural difference has reliable and proximate causal effects in the generation of a specific dysphoric trait a single region of interest abnormality hypothesis is untenable.

Strakowski and colleagues $(2005$, p. 114) in their recent summary of neuroimaging findings pertaining to bipolar disorder argue that it is fundamentally a disorder of effective or functional connectivity (Goebel et al 2004).

\footnotetext{
“...Imaging studies taken together highlight that it is unlikely that bipolar disorder will localize to abnormalities within a single neuroanatomic structure. The brain is not organized into discrete independent functional packets, but, instead consists of complex, interconnected neural networks. Therefore, dysfunction in any network will echo throughout the brain in complex and, currently,
} 
unpredictable activations. Nonetheless, taken together, these studies suggest that, in bipolar disorder, there may be a relatively diminished prefrontal modulation of subcortical and medial temporal structures within the anterior limbic network (eg, amygdala, anterior striatum and thalamus), which results in dysregulation of mood...(p. 114).

In this context, a functional lesion in any pathway is bound to adversely effect the optimal functioning of a prefrontal mediated neural network, instantiating spatiotemporally distributed higher-order cognitive processes. Indeed, Houenou and colleagues (2007; p. 1002) suggested that rather than focusing on a restricted region of the cortex or the subcortex, an approach more congruent with contemporary models of effective connectivity “....might be more reliable to investigate the characteristics of an entire white matter tract with recently developed techniques such as diffusion tensor tractography rather than exploring a single region of a fiber bundle...". Quantitative tractography can provide multiple measures with respect to reconstructed fiber tracts such as (i) number of reconstructed fibers, (ii) mean fractional anisotropy, and (iii) mean apparent diffusion coefficient of fibers.

\section{Bipolar disorder and neuropsychological findings}

Frantom and colleagues's elegant 2008 study of euthymic bipolar disorder patients (BP), their unaffected first-degree relative (FD) and healthy controls ( $\mathrm{HC}$ ) is among the most comprehensive in the literature (Frantom et al 2008). The most important finding was that the first-degree relatives scored intermediate between bipolar patients (worst) and normals (best) on 6 of 7 cognitive domains thereby providing strong evidence of a cognitive endophenotype associated with the disorder (Gottesman and Gould 2003). Significant differences were found on Block Design (Ringe et al 2002) and Benton Judgment of Line Orientation Test (Benton et al 1978) between bipolar disorder and normal healthy controls. Bipolar disorder subjects scored on average 3 scaled score points lower on Block Design than HC's, while BP's scored 22.8/30 versus HC's 26.4/30 on Judgment of Line Orientation. Visuospatial and visuo-constructional deficits have been reported previously in bipolar disorder subjects (Sapin et al 1987; Gruzeleir et al 1988; Coffman et al 1990; Bulbena and Berrios 1993; Tham et al 1997; Atre-Vaidya et al 1998; Rubinsztein et al 2000; EI Badri et al 2001).

In terms of localizing capability, Judgment of Line Orientation results in increased blood flow in the right temporo-occipital region (Hannay et al 1987), whereas the
Block Design subtest is a test of constructional praxis, sensitive to right parietal lesions (Warrington et al 1986). Frantom and colleagues (2008) were careful to note that no difference was found on Judgment of Line Orientation performance in discordant monozygotic twins, one of which was afflicted with bipolar disorder (Gourovitch et al 1999). The lack of a difference on a test of estimation of the incidental angle between two lines segments in genetically identical subjects, suggests that Judgment of Line Orientation is not part of the core bipolar endophenotype. The two different tasks are clearly not measuring the same abilities (Denes and Pizzamiglio 1999; Lezak 1995), and by default then, the core deficit must be constructional praxis.

The bipolar group was found to be impaired significantly on the Wisconsin Card Sort Test perseverative errors score (Heaton et al 1993), and the Trail Making Test Part B (Reitan and Wolfson 1985) in Frantom and colleagues' study, suggesting some loss of mental flexibility. Although the level of general intelligence was similar for the BP, FD, and HC in both the Frantom and Gourovitch twin studies, there were no group differences on either the Wisconsin Card Sort Test or Trails B in the twin study, casting doubt on the claim that a genetically-based executive function deficit is part of the bipolar affective disorder endophenotype. The executive dysfunction hypothesis negation gains support from the finding that no differences were recorded on categories achieved on the WCST or on Category Fluency (Reitan and Wolfson 1985) or Letter Fluency Tests (Benton and Hamsher Kde 1989) in the Frantom study.

Of particular interest were the covariate findings that pertain to the hypothesis that some symptomatology might be due to the adverse effects of trait-dependent mood dysregulation. Each subject was tested on the Hamilton Depression Rating Scale (Hamilton 1960) and the Young Mania Rating Scale (Young et al 1978); all BP's were medicated and no subjects met clinical indicators for mania or depression. However, when these two indicators were used as covariates the Visual Learning and Memory domain was no longer significant, paralleling the nonsignificant findings for any Verbal Learning and Memory measures. This is a helpful clinical finding and suggests that while manic-depressive symptoms may interfere negatively with verbal and visual learning and memory processes, vocational decisions such as return to work or educational initiatives could well be feasible once mood has stabilized.

This recent study's nonsignificant findings pertaining to Verbal Learning and Memory is contrary to studies showing that deficits in this domain are the most reliable 
neurocognitive markers of BP (Denicoff et al 1999; Ali et al 2000; Clark et al 2001; Zubieta et al 2001). Many of these latter studies were not as well-controlled as the Frantom study suggesting that the recent demonstration of a lack of verbal and visual memory deficits is a genuine effect. A meta-analysis with bipolar disorder subjects demonstrated an effect size of 0.90 across 10 studies using the California Verbal Learning Test (Delis et al 1987; Robinson et al 2006). However this bipolar sample had a low average of only 2.9 hospitalizations, and an onset of 24 years, with all subjects fully employed or attending university. One conclusion that could be drawn from this collective work is that neuropsychological deficits are by no means the norm, especially for subjects in the upper ability spectrum with less severe and chronic illness features.

Frantom and colleagues (2008) did find an advantage for left, as opposed to right hemisphere cognitive function composite factor, but no such effect for simple motor function. A right hemisphere disadvantage, as well as a specific visuospatial function deficit among the seven neurocognitive domains, was recorded in aggregate variable findings. The results of this well-designed study appear generalizable due to the fact that much of the previous literature related to neuropsychological deficits in bipolar disorder subjects was reviewed and integrated into the study. Finally, this study addressed a number of the limitations of previous studies including: (i) the use of a comprehensive neuropsychological battery, (ii) closely matched participants on all demographic variables, (iii) the requirement for clinical stability, (iv) the use of normal controls and first degree relatives as well as (v) the use of valid research diagnostic strategies. In view of the previous literature and careful systematic review of it, it was found that performance on Block Design was significantly impaired in BP subjects, consistent with a righthemisphere constructional apraxia.

A large population level study of 47 bipolar disorder families used a battery of laterality and relative hand skill tests, along with a quantitative transmission disequilibrium test (QTDT) and a genetic analysis of blood samples (Abecasis et al 2000). Savitz and colleagues (2007) tested for the degree of handedness as a proxy for atypical lateralization in 55 bipolar disorder I patients and 185 bipolar spectrum patients and unaffected relatives. The hypothesis was that schizophrenia, and to a lesser extent bipolar disorder are caused by a disruption in the normal process of hemispheric specialization (Crow 2000), such that the components of language which are normally localized to the left hemisphere, become bilaterally represented. The end result is that psychotics “...lose the ability to discriminate between what could be said (thought), what is said (speech output) and what is heard (speech input). Thought is confused with linguistic input or output producing feelings of thought insertion, thought broadcast and auditory hallucinations...'( p. 698) (Savitz et al 2007).

However, others such as Dewan and colleagues (1987) have found normal structural cerebral asymmetry in bipolar disorder subjects, suggesting an etiological difference between schizophrenia and bipolar disorder. Hence, the hypothesis of deficit lateralization in bipolar disorder subjects has not been supported entirely. The Savitz and colleagues (2007) study is a major forward advance in the understanding of the disorder. First of all the South African group determined that the BP cohort was significantly more lateralized on the Relative Hand Skill Test compared with asymptomatic BP relatives (Tapley and Bryden 1985), and on the Waterloo Handedness and Footedness Inventories (Elias and Bryden 1998). This finding echoes Dewan's sentiments that there are important differences between schizophrenia and bipolar disorder. In the past, the general consensus was that the proportion of mixed and left handers, connotating bilateral language representation, was significantly higher in people with schizophrenia (Dragovic and Hammond 2005; Sommer et al 2001).

However, the putative link between bipolar disorder and schizophrenia is not limited to structural MRI, neuropsychological or psychiatric symptom profile findings. Recent genome-wide scans have shown that the two disorders have linkages to 2q22.1-q23.3, 8p22, 13q31, and 22q11-13, G72/G30, BDNF, and COMT (Badner and Gershon 2002; Maier et al 2005). These genes are widely distributed in the normal population, and hence, important interactions among the various combinations of these alleles have not yet been examined. In the Savitz and colleagues (2007) study, 10 separate genes shown to have an association with bipolar disorder or bipolar disorder/schizophrenia, were assayed for in BP and first-degree relatives. The catechol-O-methyl-transferase (COMT) gene was found to significantly associate with the Relative Hand Skill test. The finding that bipolar disorder I subjects are more strongly lateralized than those with schizophrenia, implies fundamental differences in the nature of the two mental illnesses. A finding that schizophrenia is a disorder of too little hemispheric lateralization of function, and that bipolar disorder is an illness of too much lateralization, still would be congruent with Crow's (2000) thesis.

The authors speculate that excessive left-lateralized language mechanisms result in bipolar disorder, presumably 
as a consequence of the rs++ genotype (Corballis 1998). This would be consistent with Bilder and colleague's finding of greater asymmetry in bipolar as opposed to schizophrenic subjects (Bilder et al 1999). However, this hypothesis presumes that only extremely left lateralized configurations are possible and not those of extreme right lateralization. If Annett's (1985) hypothesis that rs-- random environmental events will cause one of the hemispheres to become linguistically dominant, then $50 \%$ will display left-hemisphere and 50\% will display right-hemisphere dominance (Annett 1985). In this context, the rs++ and the rs-- genotype would both be expected to produce an illness propensity-inducing endophenotype with the former much more prevalent than the latter. To digress, the Relative Hand Skill (RHS) test consists of a series of circles arranged in a repeated pattern (Tapley and Bryden 1985). The subject is asked 'to make a dot in each circle, following the pattern as quickly as you can'. The test is similar in some respects to coding subtests of the Wechsler scales without any elementary letter or symbol manipulatory requirements (Nalcaci et al 2001). For this reason the RHS test is a reliable genotypic marker and a neuropsychological test primarily of sensorimotor agility.

The poor performance of bipolar disorder subjects on the Block Design subtest and their superior performance on the RHS test could be consistent with the hypothesis that a motor speed/agility versus constructional praxis trade-off is occurring. COMT is highly localizable in terms of function to the prefrontal cortex (Gogos et al 1998), and particularly with regard to regulating dopamine in the striatum (Sesack et al 1998). Of interest with respect to neuropsychological function in bipolar disorder, was that the COMT genotype alone accounted for four percent of the variance in Wisconsin Card Sort Test perseverative errors, among individuals with schizophrenia (Egan et al 2001), and it was found to have significant effects on a factor described as speed of processing and attention (Bilder et al 2002). It appears, then, that the
COMT genotype plays an important role in determining the baseline dopaminergic tone in the prefrontal cortex, and that this relationship, in terms of performance, is an inverted U-shaped curve (Mattay et al 2003).

However, there is still a problem with the interpretation of rs-- and rs++ as two sides of the same distribution. Many recent studies have shown extreme rightward lateralization to be associated with normal or even superior intelligence and a mirror reversed pattern of spatial and linguistic functions in some, but not all subjects (Knecht et al 2001; 2003 Floel et al 2005). Crowding effects manifest as decreased constructional praxis skills (eg, Block Design); these effects are found in some, but certainly not all, atypically lateralized subjects (Knecht et al 2001, 2003; Floel et al 2005). Clearly other complex factors are involved in the etiology of bipolar disorder aside from lateralizing genes, since extreme lateralization is not necessarily associated with either neurological or psychiatric, or intellectual disabilities. Moreover, the recent findings are of theoretical interest; if the archetypal configuration of extreme asymmetry is not by necessity associated with bipolar disorder, this much alone suggests that it cannot be a causal, but can be only a contributing variable in the context of other genotypes or disease processes. Finally, extreme leftward lateralization, although possible to measure in theory with a large enough sample using transcranial doppler or fMRI, has not been systematically studied to date (Table 1).

Although complete reversibility in the lateralization of cognitive function has been previously reported, it is, however, extremely rare (Fischer et al 1991). Comprehensive single-case studies of such phenomenon in bipolar patients and atypical subjects are nonexistent. These atypical localization cases or unique co-localization scenarios can be instructive with regard to the fundamental and deep principles by which the cerebral cortex is organized. Basso and colleagues (1985) was among the first to note that such

Table I An organizational framework for understanding the relationship between cognitive phenotypes encountered with normal and atypical language localization. This is only one potential configuration and many others are possible considering the heterogeneous nature of bipolar disorder

\begin{tabular}{lll}
\hline Subject type & Left hemisphere co-localization & Right hemisphere co-localization \\
\hline Normal & I. Language & I. Emotion \\
Language & 2. Praxis & 2. Visuospatial functions \\
Localization & 3. Abstract words & 3. Concrete words \\
Atypical & I. Praxis & I. Emotion \\
Language & 2. Visuospatial functions & 2. Language \\
Localization & 3. Concrete Words & 3. Abstract words \\
\hline
\end{tabular}


subject matter can be highly informative to this line of inquiry. It is no coincidence that the publication of these landmark studies occurred with the widespread dissemination of high resolution computed tomography (CT) scan technology.

Moreover, Basso and her colleagues (1985) noted that no comprehensive theory espousing the organization of language or cognitive function could be considered complete without a theory that accounted for the "anomalies". Fischer and colleagues (1991) took a secondary step in this natural inquiry, and questioned how are different cognitive and behavioral operations related to each other in terms of functional outcome? The derivative and highly pertinent offshoot of this question is whether the intrinsic characteristics or cognitive functions of unexpectedly displaced modules change as a function of either (i) dislocation or (ii) co-localization within an unexpected hemisphere? Single and group case study of anomalous subjects using fMR-adaptation, fMRI, DTI, and cognitive neuropsychological methods could help illuminate both (i) mechanisms responsible for bipolar disorder and atypical localization, as well as those (ii) basic principles of how the brain is organized and lateralized. Thus, genetic alleles conferring some degree of bipolar susceptibility and neuropsychological endophenotypes have been described. However it is not entirely clear why such widespread and disseminated genetic markers of such traits would continue to persist in the general population.

\section{The evolutionary significance of temperamental mood dysphoria}

Traits must be explained in terms of the effects of increasing allele frequencies at a population level (Nesse 2006), or how vulnerabilities persist in the gene pool (Nesse and Williams 1994). Since low mood occurs in all cultures and reliably effects behavior; the question is how do vulnerabilities persist in the gene pool (Morris 1992). The peak onset of depression is early adulthood during the achievement of major life goals (Weissman et al 1996), stressful events that exacerbate low mood (Kessler 1997), with a normal distribution from dyphoria to depression (Ruscio and Runci 2002) highlighting the usefulness of dimensional models (Angst and Merikangas 2001). The organizing determinant for low mood is the environmental epoch that gave rise to it (Tooby and Cosmides 1990), and loss is at the core of most clinical depression. Therefore cognitive modeling of the antecedents of loss provides short-term evolutionary benefits (Nesse 2006). These benefits include an impetus to regain lost resources; motivation to do so; avoidance of eliciting situation; protection of other resources; adjustment of strategies; prevention of future losses; or making amends for accrued losses.
Moderate low mood can facilitate superior social judgement (Badcock and Allen 2003), and low mood, characteristic of neurosis has adaptation effects (Hartung 1988). One finding is that striving for status and low mood are causally related; when goals are impeded one needs a way to determine if success is possible; or one needs a means to disengage from obsolete goals; and perhaps re-establish new goals (Nesse 1999). Mood provides a measure to determine progress towards the achievement of goals (Carver and Scheier 1990), and its homeostatic regulation is designed for careful investment in the allocation of resources (Nesse 1999). Key resources include relationships, status, and kinship behavior (Krebs and Davies 1997). Disengagement, associated with low mood, allows for implementation of more productive strategies (Klinger 1975) or re-appraisal of central life goals (Gut 1989). It is theorized that dysphoric genes have selective advantages which keep them at high basal allelic frequencies in the population (Houle 1998). Moreover, it appears that absolute mood level is not optimal, but rather, the key is the facility with which a well-designed mood homeostatic mechanism selects the correct behavior at the right time. Sensation-seeking is a good example, since exposure to life events is in part due to shared genetic heritage and therefore kin groups may select the same environment eliciting the same behavioral phenotypes (Kendler and Karkowski-Shuman 1997).

Hypomania can result is sustained productivity or enhanced creativity in kin-groups (Wilson 1998). Given that the deleterious effects for bipolar are worse than unipolar depression it appears that temperamental disposition effects could be at work. Moreover, it is possible that such traits reliably lead to financial success and/or selection for physically attractive mates (Andreasen 1987: Richards et al 1988). In such a context, if the mood regulator acts as thermostat, then oscillation is naturally to be expected in cycles (Nesse 2006). Therefore, bipolar disorder could be conceptualized (i) as a defective regulation of positive feedback cycles or, (ii) more threshold level sensitivity in the servo-control mechanism's normal variance in fluctuation. The anecdotal evidence that bipolar disorder patients have particular personality and temperamental features and could be perhaps more "sensitive" than others appears congruent with recent theoretical models and empirical findings.

\section{Creativity and bipolar disorder}

Creativity requires a minimum level of high general intelligence, a well-developed fund of knowledge both 
across and within a specific domain, as well as specialized skills. However, these three components of creativity are insufficient. What does appear to be essential is the ability to develop alternative solutions to problems or the ability to use divergent thinking skills. The frontal lobes are known to be crucial in the generation of alternative strategies, just as the temporal and parietal cortices are essential in the storage of specialized knowledge (Heilman et al 2003). Heilman and colleagues hypothesize that finding the "thread that unites" requires the binding of different forms of knowledge stored in different regions and modules of the brain that might not normally be associated. Therefore, atypical localization of cognitive functions, and the attendant co-association of brain regions that are not normally connected through white matter tracts, might be essential for creative innovation (Fischer et al 1991). The high co-morbidity between both unipolar and bipolar mood disorder and creative innovation, at least within the upper quartile of the general ability range, suggests that alterations in specific neurotransmitters might be a key explanatory variable to consider.

The threshold theory of IQ and creative innovation have been reviewed elsewhere (Barron and Harrington 1981), and suggest that below an IQ of 120 is important and causally related to creative innovation. However, above a minimum IQ of 120 there is no relation between creativity and intelligence. The threshold theory would explain why William Shockley, who was the inventor of the transistor and a Nobel prize winner, and Pablo Picasso, Albert Einstein, and Charles Darwin were all noted by their primary school teachers to be dull, and in at least one case, scoring low on intelligence tests (Heilman 2005, p. 3). Therefore, general intelligence or IQ is necessary but it is not sufficient to explain creative innovation; moreover it is important to note that the link between creativity, bipolar disorder, and the achievement of eminence within a domain is just as strong in women.

Heilman (2005) notes that a high general level of background knowledge within a domain has been consistently found to be a pre-requisite for creative innovations or works. In the example of our creative geniuses above, all spent formative years perfecting and honing disparate areas of knowledge, expertise and skill before their discoveries were made. Einstein spent years studying math and physics while working at the Swiss patent office, whereas Picasso spent years first learning how to mix paints and draw forms. Finally, Darwin developed an encyclopedic knowledge of the structure and functions of previously uncatalogued species on his two-year voyage around the world.
There are some theoretical and practical reasons to suspect that the largest white matter tract in the brain may have a role in creativity. As Heilman and colleagues (p. 374) note, Rorschach tests of patients who had undergone cerebral commissurotomy revealed that they did not score high on this projective test of creativity (Heilman et al 2003; Lewis 1979). This is one of the few positive neuropsychological findings on high level cognitive processes recorded post-commissurotomy, aside from simple divided visual field, dichotic listening, or dichaptic tests. The originators of the commissurotomy for the treatment of intractable epilepsy note that incomplete hemispheric communication enabled lateralized cognition and hemispheric independence, which might be essential for the incubation of ideas in creative innovation (Bogen and Bogen 1988). Hence there is reason to speculate that the corpus callosum in the intact state, and in its pathological manifestations, could have an effect on processes associated with creative production.

\section{Writing and bipolar disorder}

Andreasen and Glick (1988) noted that bipolar disorder, with its attendant manic episodes and depression, was not causally related to creative work output. For instance, respondents noted that they were unable to work during depressive periods and that work produced during severe mania was of poor quality. Hypomanic episodes were similarly not useful since distractibility, poor concentration, and increased sociability detracted from creative drive. Pickering suggested that periods of illness, particularly depression, may be apt to facilitate the creative process, since it could provide an incubation period during which ideas may develop (Pickering 1974). Personality theory is replete with descriptions of creative individuals, and there is a remarkable degree of consistency across studies in the core attributes of: nonconforming, adventuresome, sensitive, introspective, socially detached, self-assertive, intelligent, highly independent and autonomous (MacKinnnon 1965).

These reliable personality variable findings lend support to the hypothesis that it is the temperamental factors, rather than the manic-depressive illness per se, that is responsible for the co-association of creativity and the achievement of eminence, by high ability bipolar probands. Similarly, the affective disorder patient experience of suffering may enhance the creative person's understanding of the human condition (Andreasen and Glick 1988). Andreason and Glick (1988) note that contrary to mental illness facilitating creativity, what in actual fact occurs is that psychopharmacological 
treatment of bipolar disorder almost always outweighs the side effects of the medication on the creative process, and that creative acts and works increase and not decrease; particularly with respect to writing, which requires sustained euthymic periods of equilibrium.

Most studies examining the putative relationship between creativity and bipolar disorder have studied eminently creative individuals through either structured interview, semi-structured interview, or purely biographical research methods (Andreasen 1987; Jamison 1989; Ludwig 1992; Ludwig 1994; Ludwig 1995; Post 1994). The causal link with eminent samples of bipolar disorder women and men is unequivocal and the effects are large. This sampling method, however, is fraught with technical difficulties. These problems include that such samples are by nature extreme; there no subject interviews, there is routine use of highly subjective biographical review techniques and a failure to use standard instruments. Santosa and colleagues (2007) provide an empirical study to demonstrate the creativity link in bipolar disorder subjects that are noneminent. Santosa's study is among the first to show an objectively defined causal link between bipolar disorder and enhanced creativity. These findings suggest that the notion of bipolar subjects excellence in the world of arts, literature, and the sciences may have more than a ring of truth. However the question remains, how best to optimally treat the person with bipolar disorder who demonstrates creative and other potential.

\section{Conclusions}

The results of this review suggest that for some subtypes of bipolar disorder there may well be aberrant, anomalous, or atypical lateralization of cognitive functions in the brain. The study of bipolar disorder subjects with atypical localization of cognitive functions in addition to the study of healthy subjects with atypical localization of cognitive functions can illuminate some fundamental principles by which the language and other cognitive functions are organized within the cerebral cortex. As noted by several neurolinguists an account of how cognitive function is organized in the human brain cannot be considered complete until these anomalies have been integrated into a comprehensive theory. Biographical, epidemiological, and empirical studies now suggest that creativity is enhanced in bipolar disorder probands and suggests that atypicality and hyperconnectivity of specific brain regions may account for these findings. Several behavioral neurologists have previously hypothesized that such association of brain regions that are not normally connected in the average human brain may be the causal factor involved in enhanced intuition, insight, and the production of original works.

It remains to be determined if the co-association of cognitive functions that are not normally co-localized in such bipolar subjects confers emergent higher-order cognitive functions. This much has been hypothesized previously. Systematic neuropsychological study of high ability bipolar disorder women and men who are eminent artists, writers, and scientists could potentially shed some light on the mechanisms by which the creative brain is structured and how it functions. Comprehensive study of bipolar disorder subjects using DTI tractography, full neuropsychological exams, functional MRI paradigms, systematic psychiatric assessment techniques and controls should help to elucidate the neurophysiologic mechanisms involved in this common mental illness. The effective treatment of higher ability bipolar disorder probands who demonstrate creative potential and works is also a question that should be addressed in future studies given the reliable findings pertaining to personality traits that such people possess as well as their high need for achievement and development of personal goals.

\section{Acknowledgments}

Simon M McCrea was a post-doctoral fellow and research associate of the Divisions of Neurology and Neuroophthalmology within the Faculty of Medicine at the University of British Columbia while this manuscript was prepared. The author acknowledges the funding and support of NIMH R01-MH069898 grant to Jason J.S. Barton, MD, PhD during completion of this review. Parts of this manuscript were presented at the VII Annual Meeting of the Vision Sciences Society in Sarasota, Florida from May 11th to May 16th, 2007.

\section{References}

Abecasis GR, Cardon LR, Cookson WO. 2000. A general test of association for quantitative traits in nuclear families. Am J Hum Genet, 66:279-92.

Aboitiz F, Scheibel AB, Fisher RS, et al. 1992. Fiber composition of the human corpus callosum. Brain Res, 598:143-53.

Alexander GE, DeLong MR, Strick PL. 1986. Parallel organization of functionally segregated circuits linking basal ganglia and cortex. Annu Rev Neurosci, 9:357-81.

Ali SO, Denicoff KD, Altshuler LL, et al. 2000. A preliminary study of the relation of neuropsychological performance to neuroanatomic structures in bipolar disorder. Neuropsy Neuropsy Be, 13:20-8.

Anderson AK, Christoff K, Stappen I, et al. 2003. Dissociated neural representations of intensity and valence in human olfaction. Nat Neurosci, 6:196-202.

Andreasen NC, Glick ID. 1988. Bipolar affective disorder and creativity: Implications and clinical management. Compr Psychiatry, 29:207-17.

Andreasen NC. 1987. Creativity and mental illness: Prevalence rates in writers and first- degree relatives. Am J Psychiatry, 144:1288-92. 
Angst J, Merikangas KR. 2001. Multi-dimensional criteria for the diagnosis of depression. J Affect Disorders, 62:7-15.

Annett M. 1985. Left, right, hand and brain: The right shift theory. London: Lawrence Erlbaum.

Arnold SE, Hymann BT, Van Hoesen GW. 1994. Neuropathological changes of the temporal pole in Alzheimer's disease and Pick's disease. Arch Neurol, 51:145-50.

Atre-Vaidya N, Taylor MA, Seidenberg M, Reed R, Perrine A, Glick-Oberwise F. 1998. Cognitive deficits, psychopathology, and psychosocial functioning in bipolar mood disorders. Neuropsy Neuropsy Be, 11:120-6.

Badcock, PBT, Allen NB. 2003. Adaptive social reasoning in depressed mood and depression vulnerability. Cognition Emotion, 17:647-70.

Badner JA, Gershon ES. 2002. Meta-analysis of whole-genome linkage scans of bipolar and schizophrenia. Mol Psychiatryr, 7:405-11.

Baron-Cohen S, Ring HA, Wheelwright S, et al. 1999. Social intelligence in the normal and autistic brain: An fMRI study. Eur $J$ Neurosci,11:1891-8.

Barron F, Harrington DM. 1981. Creativity, intelligence and personality. Annu Rev Psychol, 32:439-76.

Barton JJ, Cherkasova M, O'Connor M. 2001. Covert recognition in acquired and developmental prosopagnosia. Neurology, 57:1161-8.

Barton, JJ, Cherkasova M, Heftner R. 2004. The covert priming effect of faces in prosopagnosia. Neurology, 63:2062-8.

Bassett SS, Yousem DM, Cristinzio C, et al. 2006. Familial risk for Alzheimer's disease alters fMRI activation patterns. Brain, 129:1129-39.

Basso A, Lecours AR, Moraschini S, et al. 1985. Anatomoclinical correlations of the aphasias as defined through computerized tomography: Exceptions. Brain Lang, 26:201-29.

Baumgaertner A, Weiller C, Buchel C. 2002. Event-related fMRI reveals cortical sites involved in contextual sentence integration. Neuroimage, 16:736-45.

Beaulieu C, Plewes C, Paulson LA, et al. 2004. Regional correlation of fractional anisotropy in brain with reading ability in children. XII Annual Meeting of the International Society for Magnetic Resonance in Medicine, May 15-21, Kyoto, Japan.

Bechara A, Damasio AR, Damasio H, Anderson SW. 1994. Insensitivity to future consequences following damage to human prefrontal cortex Cognition, 50:7-15.

Bechara A, Damasio H, Tranel D, Damasio AR. 1997. Deciding advantageously before knowing the advantageous strategy. Science, 275:1293-5.

Benevento LA, Fallon J, Davis BJ, Rezak M. 1977. Auditory-visual interaction in single cells in the cortex of the superior temporal sulcus and the orbital frontal cortex of the macaque monkey. Exp Neurol, 57:849-72.

Benton AL, Hamsher K, Varney NR, Spreen O. 1978. Judgement of line orientation. New York: University Press.

Benton AL, Hamsher Kde S. 1989. Multilingual aphasia examination. Iowa City: AJA Associates.

Berrittini W. 2006. Genetics of bipolar and unipolar disorder. In: Stein DJ, Kupfer DJ, Schatzberg AF (eds). Textbook of mood disorders. Washington: American Psychiatric Publishing, pp. 235-47.

Berthoz S, Armony JL, Blair RJR, Dolan RJ. 2002. An fMRI study of intentional and unintentional (embarrassing) violations of social norms. Brain, 125:1696-708.

Bilder RM, Volavka J, Czobor P, et al. 2002. Neurocognitive correlates of the COMT Val(158)Met polymorphism in chronic schizophrenia. Biol Psychiatry, 52:701-7.

Bilder RM, Wu H, Bogerts B, et al. 1999. Cerebral volume asymmetries in schizophrenia and mood disorders: A quantitative magnetic resonance imaging study. Int J Psychophysiol, 34:199-205.

Binder JR, Westbury CF, McKiernan KA, et al. 2005. Distinct brain systems for processing concrete and abstract concepts. J Cognitive Neurosci, 17:905-17.

Bogen JE, Bogen GM. 1988. Creativity and the corpus callosum. Psychiatr Clin N Am, 11:293-301.
Bottini G, Corcoran R, Sterzi R, et al. 1994. The role of the right hemisphere in the interpretation of figurative aspects of language. A positron emission tomography study. Brain, 117:1241-53.

Braak H, Braak E, Bohl J. 1993. Staging of Alzheimer-related cortical destruction. Eur Neurol, 33:403-8.

Breiter HC, Aharon I, Kahneman D, Dale A, Shizgal P. 2001. Functional imaging of neural responses to expectancy and experiences of monetary gains and losses. Neuron, 30:619-39.

Bright P, Moss H, Tyler LK. 2004. Unitary vs multiple semantics: PET studies of word and picture processing. Brain Lang, 89:417-32.

Brooks JO, Hobyln J. 2005. Secondary mania in older adults. Am J Psychiatry, 162:2033-8.

Brunet E, Sarfati Y, Hardy-Bayle MC, Decety J. 2000. A PET investigation of the attribution of intentions with a nonverbal task. Neuroimage,11:157-66.

Bulbena A, Berrios GE. 1993. Cognitive function in the affective disorders: A prospective study. Psychopathology, 26:6-12.

Calarge C, Andreasen NC, O'Leary DS. 2003. Visualizing how one brain understands another: A PET study of theory of mind. Am J Psychiatry, 160:1954-64

Carmichael ST, Price JL. 1995. Limbic connections of the orbital and medial prefrontal cortex in macaque monkeys. J Comp Neurol, 363:615-41.

Carran MA, Kohler CG, O'Connor MJ, Bilker WB, Sperling MR. 2003. Mania following temporal lobectomy. Neurology, 61:770-4.

Carver CS, Scheier MF. 1990. Origins and functions of positive and negative affect: A control-process view. Psychol Rev, 97:19-35.

Castelli F, Happe F, Frith U, Frith CD. 2000. Movement and mind: A functional imaging study of perception and interpretation of complex intentional movement patterns. Neuroimage, 12:314-25.

Catani M, ffytche DH. 2005. The rises and falls of disconnection syndromes. Brain, 128:2224-39.

Chamberlain SR, Blackwell AD, Fineberg NA, Robbins TW, Sahakian BJ. 2005. The neuropsychology of obsessive compulsive disorder: The importance of failures in cognitive and behavioural inhibition as candidate endophenotype markers. Neurosci Biobehav R, 29:399-419.

Clark L, Iverson S, Goodwin G. 2001. A neuropsychological investigation of prefrontal cortex involvement of acute mania. Am J Psychiatry, 158:1605-11.

Clarke JM, Zaidel E. 1994. Anatomical-behavioral relationships: Corpus callosum morphometry and hemispheric specialization. Behav Brain Res, 64:185-202.

Coffman JA, Bornstein RA, Olson SC, Schwarzkopf S, Nasrallah HA. 1990. Cognitive impairment and cerebral structure by MRI in bipolar disorder.Biol Psychiatry, 27:1188-96.

Corballis MC. 1998. Cerebral asymmetry: Motoring on. Trends Cogn Sci, 2:152-7.

Crinion JT, Lambon-Ralph MA, Warburton EA, Howard D, Wise RJ. 2003. Temporal lobe regions engaged during normal speech comprehension. Brain, 126:1193-201.

Crinion JT, Warburton EA, Lambdon-Ralph MA, Howard D, Wise RJ. 2006. Listening to narrative speech after aphasic stroke: The role of the left anterior temporal lobe. Cereb Cortex, 16:1116-25.

Critchley HD. 2004. The human cortex responds to an interoceptive challenge. P Natl Acad Sci U S A, 101:6333-4.

Crow TJ. 2000. Bipolar shifts as disorders of the bi-hemispheric integration of language: Implications for the genetic origins of the psychotic continuum. In: Marneros A, Angst J, editors. Bipolar disorders: 100 years after manic depressive insanity. Dordrecht: Kluwer, p. 335-48.

Damasio H, Grabowski TJ, Tranel D, Ponto LL, Hichwa RD, Damasio AR. 2001. Neural correlates of naming actions and of naming spatial relations. Neuroimage, 13:1053-64.

Davidson D. 2001. Mental events. In: Essays on actions and events: Philosophical essays. New York: Oxford University Press, p. 207-28.

Davis M. 1992. The role of the amygdala in fear and anxiety. Ann Rev Neurosci, 15:353-75. 
Delis DC, Kramer JH, Kaplan E, Ober BA. 1987. The California Verbal Learning Test. New York: Psychological Corporation.

Denes G, Pizzamiglio L. 1999. Handbook of clinical and experimental neuropsychology. East Sussex, UK: Psychology Press.

Denicoff KD, Ali SO, Mirsky AF, Smith-Jackson EE, Leverich GS, Duncan CC. 1999. Relationship between prior course of illness and neuropsychological functioning in patients with bipolar disorder. $J$ Affect Disorders, 56:67-73.

Dewan MJ, Haldipur CV, Lane E, Donnelly MP, Boucher M, Major LF. 1987. Normal cerebral asymmetry in bipolar patients. Biol Psychiatry, 22:1058-66.

Divac I, Rosvold HE, Szwarcbart MK. 1967. Behavioral effects of selective ablation of the caudate nucleus. J Comp Physiol Psych, 63:184-90.

Dragovic M, Hammond G. 2005. Handedness in schizophrenia: A quantitative review of the evidence. Acta Psychiatr Scand, 111:410-9.

Duffau H, Gatignol P, Mandonnet E, et al. 2005. New insights into the anatomo-functional connectivity of the semantic system: A study using cortico-cortical electrostimulations. Brain, 128:797-810.

Duffau H. 2008. The anatomo-functional connectivity of language revisited: New insights provided by electrostimulation and tractography. Neuropsychologia, 46:927-34.

Ebeling U, von Cramon D. 1992. Topography of the uncinate fascicle and adjacent temporal fiber tracts. Acta Neurochir, 115:143-8.

Egan MF, Goldberg TE, Kolachana BS, et al. 2001. Effect of COMT val ${ }^{105 / 108}$ met genotype on frontal lobe function and risk for schizophrenia. $P$ Natl Acad Sci U S A, 98:6917-22.

El Badri SM, Ashton CH, Moore PB, Marsch VR, Ferrier IN. 2001. Electro- physiological and cognitive function in young euthymic patients with bipolar affective disorder. Bipolar Disord, 3:79-87.

Elias LJ, Bryden MP. 1998. Footedness is a better predictor of language lateralization than handedness. Laterality, 3:41-51.

Elliott R, Frith CD, Dolan RJ. 1997. Differential neural response to positive and negative feedback in planning and guessing tasks. Neuropsychologia, 35:1395-404.

Fellows LK, Farah MJ. 2005. Different underlying impairments in decision-making following ventromedial and dorsolateral frontal lobe damage in humans. Cereb Cortex, 15:58-63.

Fellows LK. 2007. The role of orbitofrontal cortex in decision making: A component process account. Ann NY Acad Sci, 1121:421-30.

Ferstl EC, von Cramon DY. 2002. What does the frontomedian cortex contribute to language processing: Coherence or theory of mind? Neuroimage, 17:1599-612.

Fischer RS, Alexander MP, Gabriel C, Gould E, Milione J. 1991. Reversed lateralization of cognitive functions in right handers: Exceptions to classical aphasiology. Brain, 114:245-61.

Fletcher PC, Frith CD, Baker SC, Shalllice T, Frackowiak RSJ, Dolan RJ. 1995b. The mind's eye precuneus activation in memory-related imagery. Neuroimage, 2:195-200.

Fletcher PC, Happe F, Frith U, Baker SC. 1995a. Other minds in the brain: A functional imaging study of "theory of mind" in story comprehension. Cognition, 57:109-21.

Floel A, Jansen A, Deppe M, et al. 2005 Atypical hemispheric dominance for attention: Functional MRI topography. J Cerebr Blood F Met, 25:1197-208.

Flynn DD, Mash DC. 1986. Characterization of L-[3H] nicotine binding in human cerebral cortex: Comparison between Alzheimer's disease and the normal. J Neurochem, 47:1948-54.

Frantom LV, Allen DN, Cross CL. 2008. Neurocognitive endophenotypes for bipolar disorder. Bipolar Disord, 10:387-99.

Frith U, Frith CD. 2003. Development and neurophysiology of mentalizing. Philos T Roy Soc B, 358:459-73.

Frith U. 2001. Mind blindness and the brain in autism. Neuron, 32:969-79.

Gainotti G, Barbier A, Marra C. 2003. Slowly progressive defect in recognition of familiar people in a patient with right anterior temporal atrophy. Brain, 126:792-803.
Gallagher HL, Happe F, Brunswick N, Fletcher PC, Frith U, Frith CD. 2000. Reading the mind in cartoons and stories: An fMRI study of 'theory of mind' in verbal and nonverbal tasks. Neuropsychologia, 28:11-21.

Gallagher HL, Jack AI, Roepstorff A, Frith CD. 2002. Imaging the intentional stance in a competitive game. Neuroimage, 16:814-21.

Gentileschi V, Sperber S, Spinnler H. 2001. Crossmodal agnosia for familiar people as a consequence of right infero-polar temporal atrophy. Cognitive Neuropsych, 18:439-63.

German TP, Niehaus JL, Roarty MP, Giesbrecht B, Miller MB. 2004. Neural correlates of detecting pretense: Automatic engagement of the intentional stance under covert conditions. J Cognitive Neurosci, 16:1805-17.

Glosser G, Zwil AS, Glosser DS, O'Connor MM, Sperling MR. 2000. Psychiatric aspects of temporal lobe epilepsy before and after anterior temporal lobectomy. J Neurol Neurosur Ps, 68:53-8.

Goebel R, Roebroeck A, Kim D-S, et al. 2004. A framework for the investigation of directed cortical interactions: Theoretical background and application to dynamic sensorimotor mapping. In: Kanwisher, N, Duncan J (eds). Functional neuroimaging of visual cognition: Attention and performance XX. New York: Oxford University Press, p. 439-62.

Goel V, Grafman J, Sadato N, Hallet M. 1995. Modeling other minds. Neuroreport, 6:1741-6.

Gogos JA, Morgan M, Luine V, et al. 1998. Catechol-O-methyltransferasedeficient mice exhibit sexually dimorphic changes in catecholamine levels and behavior.P Natl Acad Sci U S A, 95:9991-6.

Goldman-Rakic PS, Porrino LJ. 1985. The primate mediodorsal (MD) nucleus and its projection to the frontal lobe. J Comp Neurol, 242:535-60.

Gottesman II, Gould TJ. 2003. The endophenotype concept in psychiatry. Etymology and strategic intentions. Am J Psychiatry, 160:636-45.

Gottfried JA, O'Doherty J, Dolan RJ. 2003. Encoding predictive reward value in human amygdala and orbitofrontal cortex. Science, 310:1104-7.

Gottfried JA, O'Doherty JP, Dolan RJ. 2002. Appetitive and aversive olfactory learning in humans studied using event-related functional magnetic resonance imaging. J Neurosci, 22:10829-37.

Gourovitch M, Torrey EF, Gold JM, Randolph C, 1999. Weinberger D, Goldberg T. Neuropsychological performance of monozygotic twins discordant for bipolar disorder. Biol Psychiatry, 45:639-46.

Gruzeleir J, Seymour K, Wilson L, Jolley A, Hirsch S. 1988. Impairments on neuropsychiatric tests of temporohippocampal and frontohippocampal functions and word fluency in remitting schizophrenia and affective disorders. Arch Gen Psychiatry, 45:623-9.

Gut E. 1989. Productive and unproductive depression. New York: Basic Books.

Hamilton M. 1960. A rating scale for depression. J Neurol Neurosur Ps, 23:53-62.

Hannay HJ, Falgout JC, Leli DA, Kathali CR, Halsey JHJr, Wills EL. 1987. Focal right temporo-occipital blood flow changes associated with judgement of line orientation. Neuropsychologia, 25:755-63.

Hartung J. Deceiving down. In: Lockard JS, Paulhus D, editors. 1988. Self-deception: An adaptive mechanism. Englewood Cliffs, NJ: Prentice-Hall, p. 170-85.

Heaton RK, Chelune GJ, Talley JL, Kay GG, Curtis G. 1993. Wisconsin Card Sorting Test (WCST) Manual - Revised and Expanded. Odessa, FL: Psychological Assessment.

Heilman KM, Nadeau SE, Beversdorf DO. 2003. Creative innovation: Possible brain mechanisms. Neurocase, 9:369-79.

Heilman KM, Valenstein E. 2003. Clinical Neuropsychology. Fourth Ed. New York: Oxford University Press.

Heilman KM. Creativity and the brain. New York: Psychology Press; 2005.

Hornak J, O’Doherty J, Bramham J, et al. 2004. Reward-related reversal learning after surgical excisions in orbito-frontal or dorsolateral prefrontal cortex in humans. $J$ Cognitive Neurosci, 16:463-78.

Houenou J, Wessa M, Douaud G, et al. 2007. Increased white matter connectivity in euthymic bipolar patients: Diffusion tensor tractography between the subgenual cingulate and the amygdalo-hippocampal complex. Mol Psychiatry, 12:1001-10. 
Houle D. 1998. How should we explain variation in genetic variation in traits? Genetica, 102/103:241-53.

Iacoboni M, Lieberman MD, Knowlton BJ, et al. 2004. Watching social interactions produces dorsomedial prefrontal and medial parietal BOLD fMRI signal increases compared to a resting baseline. Neuroimage, 21:1167-73.

James TW, Gauthier I. 2004. Brain areas engaged during visual judgements by involuntary access to novel semantic information. Vision Res, 44:429-39.

Jamison KR. 1989. Mood disorders and patterns of creativity in British writers and artists. Psychiatry, 52:125-34.

Johnson TN, Rosvold HE, Mishkin M. 1968. Projections from behaviourally defined sectors of the prefrontal cortex to the basal ganglia, septum, and diencephalon of the monkey. Exp Neurol, 21:20-34.

Jones DK, Catani M, Pierpaoli C, et al. 2006. Age effects on diffusion tensor magnetic resonance imaging tractography measures of frontal cortex connections in schizophrenia. Hum Brain Mapp, 27:230-8.

Jorge ER, Robinson RG, Starkstein SE, Arndt SV, Forrester AW, Weisler FH. 1993. Secondary mania following traumatic brain injury. Am J Psychiatry, 150:916-21.

Kanaan RA, Shergill SS, Barker GJ, et al. 2006. Tract-specific anisotropy measurements in diffusion tensor imaging. Psychiatr Res, 146:73-82.

Kendler KS, Karkowski-Shuman L. 1997. Stressful life events and genetic liability to major depression: Genetic control of exposure to the environment? Psychol Med, 27:539-47.

Kessler RC. 1997. The effects of stressful life events on depression. Annu Rev Psychol, 48:191-214.

Kim H, Shimojo S, O'Doherty JP. 2006. Is avoiding an aversive outcome rewarding? Neural substrates of avoidance learning in the human brain. PLoS Biol, 4:e233.

Kling AS, Steklis HD. 1976. A neural substrate for affiliative behaviour in nonhuman primates. Brain Behav Evolut, 13:216-38.

Klinger E. 1975. Consequences of commitment to and disengagement from incentives. Psychol Rev, 82:1-25.

Knecht S, Drager B, Floel A, et al. 2001. Behavioral relevance of atypical language lateralization in healthy subjects. Brain, 124:1657-65.

Knecht S, Jansen A, Frank A, et al. 2003. How atypical is atypical language dominance? Neuroimage, 18:917-27.

Krebs JR, Davies NB. 1997. Behavioral ecology: An evolutionary approach. Oxford, UK: Blackwell Science.

Kubicki M, Westin C-F, Maier SE, et al. 2002. Uncinate fasciculus findings in schizophrenia: A magnetic resonance diffusion tensor imaging study. Am J Psychiatry, 159:813-20.

Lewis RT. 1979. Organic signs, creativity, and personality characteristics of patients following cerebral commissurotomy. Clin Neuropsychology, $1: 29-33$

Lezak MD. 1995. Neuropsychological assessment - Third edition. New York: Oxford University Press.

Ludwig AM. 1992. Creative achievement and psychopathology: Comparison among professions. Am J Psychother, 46:330-56.

Ludwig AM. 1994. Mental illness and creative activity in female writers. Am J Psychiatry, 151:1650-6.

Ludwig AM. 1995. The Price of Greatness. New York: The Guilford Press.

Luke KK, Liu HL, Wai YY, Wan YL, Tan LH. 2002. Functional anatomy of syntactic and semantic processing in language comprehension. Hum Brain Mapp, 16:133-45.

MacKinnnon DW. 1965. Personality and the realization of creative potential. Am Psychol, 20:273-81.

Maguire EA, Frith CD, Morris RG. 1999. The functional neuroanatomy of comprehension and memory: The importance of prior knowledge. Brain, 122:1839-50.

Maier W, Hofgen B, Zobel A, Rietschel M. 2005. Genetic models of schizophrenia and bipolar disorder: Overlapping inheritance or discrete genotypes? Eur Arch Psy Clin N, 255:159-66.

Mandonnet E, Nouet A, Gatignol P, et al. 2007. Does the left inferior longitudinal fasciculus play a role in language? A brain stimulation study? Brain, 130:623-9.
Mattay, VS, Goldberg, TE, Fera, F, et al. 2003. Catechol O-methyltransferase $\mathrm{val}^{158}$ - met genotype and individual variation in the brain response to amphetamine. P Natl Acad Sci U S A, 100:6186-91.

Mayberg HS. 2006. Brain imaging. In: Stein DJ, Kupfer, DJ, Schatzberg $\mathrm{AF}$ (eds). The textbook of mood disorders. Washington: American Psychiatric Publishing, pp. 219-34.

Mishkin M, Manning FJ. 1978. Nonspatial memory after selective prefrontal lesions in monkeys. Brain Res, 143:313-23.

Mitchell JP, Macrae CN, Banaji MR. 2006. Dissociable medial prefrontal contributions to judgements of similar and dissimilar others. Neuron, 50:655-63.

Moran MA, Mufson EJ, Mesulam MM. 1987. Neural inputs to the temporopolar cortex of the rhesus monkey. J Comp Neurol, 256:88-103.

Morecraft RJ, Geula C, Mesulam MM. 1992. Cytoarchitecture and neural afferents of orbitofrontal cortex in the brain of the monkey. J Comp Neurol, 323:341-58.

Morris WN. 1992. A functional analysis of the role of mood in affective systems. Rev Pers Soc Psychol, 21:736-46.

Munari C, Kahane P, Tassi L, et al. 1993. Intracerebral low frequency electrical stimulation: A new tool for the definition of the epileptogenic area? Acta Neurochir, 58:181-5.

Murai T, Fuijimoto S. 2003. Rapid cycling bipolar disorder after temporal polar damage. Brain Injury, 17:355-8.

Nakamura K, Kubota K. 1996. The primate temporal pole: Its putative role in object recognition and memory. Behav Brain Res, 77:53-77.

Nalcaci E, Kalaycioglu C, Cicek M, Genc Y. 2001. The relationship between handedness and fine motor performance. Cortex, 37:493-500.

Nesse RM, Williams GC. 1994. Why we get sick: The new science of Darwinian medicine. New York: Vintage.

Nesse RM. 2006. Evolutionary explanations for mood and mood disorders. In: Stein DJ, Kupfer, DJ, Schatzberg AF, editors. Textbook of mood disorders. Washington: American Psychiatric Publishing, p.159-75.

Nesse, R.M. 1999. The evolution of hope and despair. J Soc Issues, 66:429-69.

Noppeney U, Price CJ. 2004. Retrieval of abstract semantics. Neuroimage, 22:164-70.

O'Doherty J, Kringelbach ML, Rolls ET, Hornack J, Andrews C. $2001 \mathrm{~b}$. Abstract reward and punishment representations in the human orbitofrontal cortex. Nat Neurosci, 4:95-102.

O’Doherty J, Rolls ET, Francis S, Bowtell R, McGlone F. 2001a. Representation of pleasant and aversive taste in the human brain. J Neurophysiol, 85:1315-21.

O’Doherty JP, Deichmann R, Critchley HD, Dolan RJ. 2002. Neural responses during anticipation of a primary taste reward. Neuron, 33:815-26.

O'Doherty JP. 2007. Lights, camembert, action! The role of the human orbitofrontal cortex in encoding stimuli, rewards, and choices. Ann NY Acad Sci, 1121:254-72.

Ohnishi T, Moriguchi Y, Matsuda H, et al. 2004. The neural network for the mirror system and mentalizing in normally developed children: An fMRI study. Neuroreport, 15:1483-7.

Olson IR, Plotzker A, Ezzyat Y. 2007. The enigmatic temporal pole: A review of findings on social and emotional processing. Brain, 130:1718-31.

Padoa-Schioppa C. 2007. Orbitofrontal cortex and the computation of economic value. Ann NY Acad Sci, 1121:232-53.

Perani D, Cappa SF, Schnur T, et al. 1999. The neural correlates of verb and noun processing - A PET study. Brain, 122:2337-44.

Pickering G. 1974. Creative malady. New York: Oxford University Press.

Post F. 1994. Creativity and psychopathology: A study of 291 world-famous men. Brit J Psychiatry, 165:22-34.

Price CJ, Wise RJS, Warburton EA, et al. 1996. Hearing and saying: The functional neuro-anatomy of auditory and word processing. Brain, 119:919-31.

Purves P, Seltzer B. 1986. The topography of commissural fibers. In: Lepore F, Pitto M, Jasper HH (eds). Two hemispheres - one brain: Functions of the corpus callosum. New York: Alan R. Liss, pp. 7-73. 
Ray JP, Price JL. 1993. The organization of projections from the mediodorsal nucleus of the thalamus to orbital and medial prefrontal cortex in macaque monkeys. J Comp Neurol, 337:1-31.

Reitan RM, Wolfson D. 1985. The Halstead-Reitan neuropsychological test battery: Theory and clinical interpretation. Tucson, AZ: Neuropsychology Press.

Richards RL, Kinner DK, Lunde I, Benet M, Merzel APC. 1988. Creativity in manic- depressives, cyclothymes and their normal first-degree relatives: A preliminary report. J Abnorm Psychol, 97:281-8.

Ringe WK, Saine KC, Lacritz LH, Hynan LS, Cullum CM. 2002. Dyadic short forms of the Wechsler Adult Intelligence Scale - III. Psychol Assessment, 9:254-60.

Roberts AC. 2006. Primate orbitofrontal cortex and adaptive behaviour. Trends Cogn Sci, 10:83-90.

Robinson L, Thompson J, Gallagher P, et al. 2006. A meta-analysis of cognitive deficits in euthymic patients with bipolar disorder. J Affect Disorders, 93:105-15.

Rolls ET, Hornak J, Wade D, McGrath J. 1994. Emotion-related learning in patients with social and emotional changes associated with frontal lobe damage. J Neurol Neurosur Ps, 57:1518-24.

Rubinsztein JS, Michael A, Paykel ES, Sahakian BJ. 2000. Cognitive impairment in remission in bipolar affective disorder. Psychol Med, 20:1025-36.

Ruscio J, Runci A. 2002. A structure-based approach to psychological assessment: Matching measurement models to latent structure. Assessment, 9:4-16.

Sakai KL. 2005. Language acquisition and brain development. Science, 310:815-19.

Santosa CM, Strong CM, Nowakowska C, Wang PW, Rennicke CM, Ketter TA. 2007. Enhanced creativity in bipolar patients: A controlled study. $J$ Affect Disorders, 100:31-9.

Sapin LR, Berrittini WH, Nurnberger JI Jr, Rothblat LA. 1987. Mediational factors underlying cognitive changes and laterality in affective illness. Biol Psychiatry, 22:979-86.

Savitz J, van der Merwe L, Solms M, Ramesar R. 2007. Lateralization of hand skill in bipolar affective disorder. Genes Brain Behav, 6:698-705.

Saxe R, Powell LJ. 2006. It's the thought that counts: Specific brain regions for one component of theory of mind. Psychol Sci, 17:692-9.

Schultz RT, Grelotti DJ, Klin A, et al. 2003. The role of the fusiform face area in social cognition: Implications for the pathophysiology of autism. Philos T Roy Soc B, 358:415-27.

Scott SK, Blank CC, Rosen S, Wise RJ. 2000. Identification of a pathway for intelligible speech in the left temporal lobe. Brain, 123:2400-6.

Scott SK, Leff AP, Wise RJ. 2003. Going beyond the information given: A neural system supporting semantic interpretation. Neuroimage, 19:870-6.

Sesack SR, Hawrylak VA, Matus C, Guido MA, Levey AI. 1998. Dopamine axon varicosities in the prelimbic division of the rat prefrontal cortex exhibit sparse immunoreactivity for the dopamine transporter. $J \mathrm{Neu}$ rosci, 18:2697-708.

Sevostianov A, Horwitz B, Nechaev V, Williams R, Fromm S, Braun AR. 2002. fMRI study comparing names versus pictures of objects. Hum Brain Mapp, 16:168-75.

Singer W. 2004. Time as a coding space in the cerebral cortex. In: Kanwisher $\mathrm{N}$, Duncan J (eds). Functional neuroimaging of visual cognition: Attention and performance XX. New York: Oxford University Press, pp. 99-123.

Small DM, Gregory MD, Mak YE, Gitelman D, Mesulam MM, Parrish T. 2003. Dissociation of neural representation of intensity and affective valuation in human gustation. Neuron, 39:701-11.

Snook L, Paulson LA, Roy D, et al. 2004. Diffusion tensor imaging of neurodevelopment in adolescents and young adults. XII Annual Meeting of the International Society for Magnetic Resonance in Medicine, May 15-21, Kyoto, Japan.

Snowden JS, Thompson JC, Neary D. 2004. Knowledge of famous faces and names in semantic dementia. Brain, 127:860-72.

Sommer I, Aleman A, Ramsey N, Bouma A, Kahn R. 2001. Handedness, language lateralization and anatomical asymmetry in schizophrenia. Brit J Psychiatry, 178:344-51.
Stowe LA, Broere CA, Paans AM, et al. 1998. Localizing components of a complex task: Sentence processing and working memory. Neuroreport, 9:2995-9.

Strakowski SM, Delbello MP, Adler CM. 2005. The functional neuroanatomy of bipolar disorder: A review of neuroimaging findings. Mol Psychiatry, 10:105-16.

Strakowski SM, Woods BT, Tohen M, et al. 1993. MRI subcortical signal hyperintensities in mania at first hospitalization. Biol Psychiatry, 33:204-6.

Tapley SM Bryden MP. 1985. A group test for the assessment of performance between the hands. Neuropsychologia, 23:215-21.

Tham A, Engelbrektson K, Mathe AA, Johnson L, Olsson E, Aberg-Wistedt A. 1997. Impaired neuropsychological performance in euthymic patients with recurring mood disorders. J Clin Psychiatry, 58:26-9.

Tooby J, Cosmides L. 1990. The past explains the present: Emotional adaptations and the structure of ancestral environments. Ethol Sociobiol, $11: 375-424$

Tremblay L, Schultz W. 1999. Relative reward preference in primate orbitofrontal cortex. Nature, 398:704-8.

Tusa RJ, Ungerleider LG. 1985. The inferior longitudinal fasciculus: A re-examination in humans and monkeys. Ann Neurol, 18:583-91.

Ursu S, Carter CS. 2005. Outcome representations, counterfactual comparisons and the human orbitofrontal cortex: Implications for neuroimaging studies of decision- making. Cognitive Brain Res, 23:51-60.

Van Hoesen G, Pandya DN, Butters N. 1975. Some connections of the entorhinal (area 28) and perirhinal (area 35) cortices of the rhesus monkey II: Frontal lobe afferents. Brain Res, 95:25-38.

Vandenberghe R, Price C, Wise R, Josephs O, Frackowiak RSJ. 1996. Functional anatomy of a common semantic system for words and pictures. Nature, 383: 254-6.

Vigneau M, Beaucousin V, Herve PY, et al. 2006. Meta-analyzing left hemisphere language areas: Phonology, semantics, and sentence processing. Neuroimage, 30:1414-32.

Vingerhoets G, Van Borsel J, Tesink C, et al. 2003. Multilingualism: An fMRI study. Neuroimage, 20:2181-96.

Vogeley K, Bussfeld P, Newen A, et al. 2001. Mind reading: Neural mechanisms of theory of mind and self-perspective. Neuroimage, 14:170-81.

Vogt BA, Pandya DN. 1987. Cingulate cortex of the rhesus monkey II: Cortical afferents. J Comp Neurol, 262:271-89.

Vollm BA, Taylor ANW, Richardson P, et al. 2006. Neuronal correlates of theory of mind and empathy: A functional magnetic resonance imaging study in a nonverbal task. Neuroimage, 29:90-8.

von Kriegstein K, Eger E, Kleinschmidt A, Giraud AL. 2003. Modulation of neural responses to speech by directing attention to voices or verbal content. Cognitive Brain Res, 17:48-55.

Walter H, Adenzato M, Ciaramidaro A, Enrici I, Pia L, Bara BG. 2004. Understanding intentions in social interaction: The role of the anterior paracingulate cortex. J Cogn Neurosci, 16:1854-63.

Wang F, Jackowski M, Kalmar JH, et al. 2008. Abnormal anterior cingulum integrity in bipolar disorder determined through diffusion tensor imaging. Brit J Psychiatry, 193:126-9.

Wang F, Kalmer JH, Edmiston E, et al. 2008. Abnormal corpus callosum integrity in bipolar disorder: A diffusion tensor imaging study. Biol Psychiatry, 64:730-3.

Warrington EK, James M, Maciejewski C. 1986. The WAIS as a lateralizing and localizing diagnostic instrument: A study of 656 patients with unilateral cerebral lesions. Neuropsychologia, 24:223-39.

Weisberg RW. 1999. Creativity and knowledge: A challenge to theories. In Sternberg RJ, editor. Handbook of creativity. Cambridge, MA: Cambridge University Press, p. 226-50.

Weissman MM, Bland RC, Canino GJ. 1996. Cross-national epidemiology of major depression and bipolar disorder. JAMA, 276:293-6.

Wilson DR. 1998. Evolutionary epidemiology and manic depression. $\mathrm{Br} J$ Med Psychol, 71:375-95.

Wilson FA, Scalaidhe SP, Goldman-Rakic PS. 1993. Dissociation of object and spatial processing domains in primate prefrontal cortex. Science, 260:1955-8. 
Young RC, Biggs JT, Ziegler VE, Meyer DA. 1978. A rating scale for mania: Reliability, validity, and sensitivity. Brit J Psychiatry, 133:429-35.

Yurgelun-Todd DA, Silveri MM, Gruber SA, et al. 2007. White matter abnormalities observed in bipolar disorder: A diffusion tensor imaging study. Bipolar Disord, 9:504-12.
Zald DH, Kim SW. 1996. Anatomy and function of the orbital frontal cortex. I: Anatomy, neurocircuitry, and obsessive-compulsive disorder. $J$ Neuropsychiatry Clin Neurosci, 8:125-38.

Zubieta J, Huguelet P, O’Neill RL, Giordani BJ. 2001. Cognitive function in euthymic bipolar I disorder. Psychiat Res, 102:9-20. 
